SOIL MACROSTRUCTURE AS AFFECTED BY CULTURAL TREATMENTS

RALPH C. COLE 



\title{
SOIL MACROSTRUCTURE AS AFFECTED BY CULTURAL TREATMENTS ${ }^{1}$
}

\author{
RALPH C. COLE'
}

\section{INTRODUCTION}

This InVESTIGATION was undertaken to find a quantitative method of expressing the structural condition of the soil, and by means of this method to study the effects of various mechanical treatments with respect to changes in structure. The effects of irrigation and of tillage operations were of particular concern. Seasonal changes were also observed.

Shaw $(17)^{3}$ has defined soil structure as :

A term expressing the arrangement of individual grains and aggregates that make up the soil mass. The structure may refer to the natural arrangement of the soil when in place and undisturbed or to the soil at any degree of disturbance. The terms used indicate the character of the arrangement, the size and shape of the aggregates, and in some cases may indicate the consistence of those aggregates.

As thus defined, the term "soil structure" is obviously descriptive, and as such is not capable of being expressed by any specific measurement or number.

Many measurements of the physical properties of soils, which are dependent on the structure, have been made; and any of these measurements may be considered as an index of soil structure. These measurements are made either of the macro- or microstructure. A greater amount of work has been done on the microanalysis, which has been mainly measurements of the size distribution of particles after the soil has been slaked in water. The macroanalyses have been mainly measurements of the size distribution of coarse aggregates of soils obtained under field conditions in an undisturbed state. This present investigation is of the latter type; the method will be described in detail later. Other methods, such as the pull on the drawbar of a tillage implement, the amount of pressure required to force a sharpened instrument into the soil, and porosity measurements such as water penetration, air movement, so-called "capillary and noncapillary" pore space, and measurements of volume weight, have been used as indexes of soil structure.

\footnotetext{
${ }^{1}$ Received for publication November 1, 1937.

${ }^{2}$ Instructor in Soil Technology and Junior Soil Technologist in the Experiment Station.

${ }^{3}$ Italic figures in parentheses refer to "Literature Cited," at the end of this paper.
} 
The work here reported was carried out on soils of the Yolo, Denverton, and Capay series, on the University Farm at Davis, California, and on private farms nearby. Quantitative measurements were made of the changes in the size distribution of aggregates after tillage operations and irrigations, and of changes directly attributable to changes in the seasons. The studies on the effect of tillage operations were made in orchards, in fields in the preparation of seedbeds, and in test plots for special-study purposes.

The tillage operations in orchards were for the express purpose of controlling weeds. Those in the preparation of seedbeds were variable and dependent upon the season in which the crop was to be planted and the nature of the crop itself. In some of the seedbed preparations, preirrigations were made to insure an adequate moisture supply before seeding.

\section{REVIEW OF LITERATURE}

In this brief review of literature, no attempt is made to discuss all of the work that has been done on soil structure. A few papers dealing with each phase are mentioned, even though some of them bear rather indirectly on this investigation.

Russell (15), at Rothamsted, investigating the factors of importance in crumb formation in soils, found that clay particles can form strong aggregates or crumbs when dry, only if the clay particles are sufficiently small, if there are a sufficient number of small exchangeable ions on the clay, and if the clay has been dried from a dispersion medium whose molecules are polar and sufficiently small. Tiulin (18) in Russia, Demolon and Henin (9) in France, Novak (14) in Czechoslovakia, Bouyoucos (2), Baver and Rhodes (1), and Cole and Edlefsen $(6,10)$ in the United States, all have measured water-stable aggregates by sedimentation, or by wet sieving and sedimentation, as indexes of soil structure. In most cases, these workers recognize that certain aggregates are fairly stable in water, and that in some cases very drastic treatments are necessary to break them down materially. Demolon and Henin (9) and Tiulin (18) describe soil aggregates as being of two kinds : those that are water-stable are formed with clays whose base-exchange cations are dibasic, and those stable only in the dry condition are formed from compression, or with clays whose base-exchange cations are monobasic. All of the workers referred to are in accord in the belief that the formation of aggregates takes place as soils are being dried out. Vilensky (20) has shown that soils which give the greatest stability against slaking and require the greatest force for deformation of dry aggregates have definite moisture ranges. 
In macroaggregate analysis, the work of Keen (12) and his associates is among the first. In this work, samples were obtained during tillage operations by cutting out rough cubes of soil with a spade and transferring them to a nest of sieves. The sieves were gently shaken a definite number of times and the material retained on each sieve was. weighed. Chapman (5) observed that two plots on the North Dakota Experimental Farm were widely different in structure and measured this difference by sieve analysis of air-dry samples taken from each plot. Hoffman ${ }^{4}$ determined the size distribution of aggregates before and after tillage with various kinds of implements. He used a 14-inch cylinder, which was driven into the soil to the depth of tillage and then inserted a steel plate under the cylinder to permit the removal of the soil in an undisturbed condition. The sample was then transferred to a graded nest of sieves that were shaken by hand and the weights determined. He was able to get good agreement between replications with the few tests made.

Keen (12) and his co-workers have used the drawbar pull on tillage implements which they measured with dynamometers to indicate the differences in soil structure. They also used the depth of penetration of a sharpened instrument into the soil under definite impact as a means of measuring the compaction. Davis (8) has further perfected this apparatus with a mechanical data recorder, and has used it extensively. Another even simpler and less expensive implement of this type has been designed and used by Culpin ( 7 ). This instrument also has a self-recording attachment.

The measurement of the porosity of soil by permeability of gases and liquids has been used as a means of studying certain physical properties. Bouyoucos (3) has devised a method of measuring water penetration by slaking a definite quantity of soil on a filter paper in a Buchner funnel and then applying suction. Methods of studying permeability by means of various kinds of tubes are too numerous to mention here. Buehrer (4) at Arizona has devised a method of passing air through soils under definite conditions of compaction, and using the values thus obtained to define soil structure. Dojarenko (according to Krause, 13) in Russia has measured the so-called "capillary and noncapillary" pore space as an expression of the soil structure, considering these values to be much more expressive of the physical properties of field soils than volume-weight expressions where the total pore space alone is calculated. The determination of capillary and noncapillary pore space is made by taking a column of soil $10 \mathrm{~cm}$ high, setting it on a piece of filter paper that is in contact with a free water surface, and permitting the soil to absorb as

\footnotetext{
${ }^{4}$ Hoffman, A. H. Unpublished manuseript.
} 
much water as possible in 48 hours. The volume of water retained under these conditions is known as "capillary pore space" and the remainder of the pore space is considered "noncapillary pore space." He designed a special tube $10 \mathrm{~cm}$ high with a volume of $100 \mathrm{cc}$ for obtaining samples in an undisturbed state. The principal objection to this measurement is that the amount of water that can be absorbed by any given soil will depend on the height of the column.

\section{EXPERIMENTAL METHODS}

Soils.-The soils on which experiments were carried out are of the Yolo, Capay, and Denverton series. These are all mineral secondary soils derived from sedimentary rock sources.

The Yolo soils are recent alluvial soils occupying smooth, gently sloping alluvial fans. There are wide variations in textural types within this series. Normally the surface soils are friable, but they become easily puddled under improper management. The subsoils are loose and friable, and of various textures. Stratification is common in the subsoil. Drainage is adequate and root and water penetration through the soil is excellent.

The soils of the Capay series are closely related to those of the Yolo series but are found further out on the alluvial fans with flatter relief and somewhat restricted drainage. The surface textures are heavy, usually of clay texture, and exhibit an adobe structure. When wet, these soils are very sticky, and when dry, large cracks occur which leave the soil in large hard adobelike blocks. The subsoil is of somewhat heavier texture than the surface soil, and is considerably compacted. This greatly inhibits root and water penetration. During the rainy season, water often stands in pools on the surface for a considerable period of time. As the water disappears from the surface, the surface soil dries rapidly and adobe cracks form, but the subsoil remains saturated for a considerable period of time after the surface soil becomes dry. The water table is often found within 6 feet of the surface in these soils.

The Denverton soils occupy high rolling terraces, often with fairly steep slopes. The profiles are immature to semimature in stage of development. Surface textures are usually heavy clay loams or clays that have definite adobe structures. Unlike those of the Capay soils, however, the adobe blocks have a large number of secondary cracks. This condition renders the surface soil very friable. The large adobe blocks break down readily to small angular units which are fairly stable. The subsoil is somewhat compact yet it is moderately permeable to roots and water. The physical properties of these soils are far more favorable to root and 
water penetration and to cultural treatments than the soils of the Capay series. Owing to their irregular relief, however, they are seldom brought under irrigation.

Method of Sampling.-The samples were taken to tillage depth in the case of cultivation tests, and to specified depths in the case of irrigation tests and studies of seasonal variations, by driving a 14 -inch steel cylinder into the soil, excavating the soil from around the cylinder, and driving a piece of sheet steel under it to remove the samples without disturbing the structure. The samples thus obtained were carefully transferred to orchard lug boxes and permitted to dry slowly under shelter.

In 1935, the percentages of moisture and the volume weights were obtained at the time the samples were collected.

Volume-Weight Determinations.-During the 1935 season, a method was found for determining the volume weight of the soil as samples were being taken for aggregate analyses. The volume weight was measured by using the same cylinder and sample as was used for sampling for aggregate analysis. After a sample had been removed from the ground as described under "Methods of Sampling," a straight-edge was placed across the top of the tube, and from 75 to 100 measurements, spaced systematically over the surface, were made from this straight edge to the surface of the soil in the cylinder. This permitted calculating the portion of the cylinder unoccupied by the sample. The difference between this figure and the total volume gave the volume of the sample. Aliquot moisture samples were taken in duplicate, from the soil right next to where the sample had been removed, and these were used as the moisture content of the sample in calculating its volume weight. The entire sample was weighed as it was taken from the field, and from the data thus obtained the volume weight was calculated. Replicates agreed within 5 per cent, which is considered good for this type of sampling. In all volume-weight determinations here reported the figures quoted are averages of 4 replicates.

Method of Sifting.- The air-dry samples were sifted in two stages: first through a nest of very coarse sieves, then in a Ro-tap shaker.

The nest of coarse sieves (designed especially for this purpose) is made of wooden boxes 8 inches deep and $2 \times 3$ feet inside dimensions with rods or pipes to form the sieves, the diameters being proportioned to the size of the opening. The coarsest screen has $1 \frac{1}{8}$-inch rods set 6 inches apart on center, which gives openings of $47 / 8$ inches; the next has $3 / 4$-inch rods 4 inches apart on center, which gives openings of $31 / 4$ inches; and the third screen has $3 / 8$-inch rods 2 inches apart on center, which gives $15 / 8$ inch openings. The fourth is a box of the same size with a solid bottom, 
in which the material passing through the finest sieve is caught. These are nested in a frame and held in place by dowels. This frame is mounted on wheels which fit on tracks of 2-inch angle iron. The tracks have stops at each end that permit a 24-inch movement of the nest of sieves. These tracks are mounted on rockers, which rock the frame while it is being rolled along the tracks. Twelve shakings of this sieve are sufficient to separate the sample to its various sizes.

The material collected in the solid box of the large shaker was sifted in a Tyler Ro-tap shaker. The sieves have openings of approximately $3 / 4,3 / 8$, $3 / 16,3 / 32,3 / 64$, and $3 / 128$ inch. The first two are unnumbered, but the last four are 4, 8, 14, and 28 mesh, respectively. The material fine enough to pass through the finest mesh was caught on a solid pan that could be nested with the sieves. As only 3 pounds of soil can be shaken in this machine at one time, a number of determinations were necessary for each sample.

The Ro-tap shaker is operated with an electric motor and has a speed of about 150 shakes a minute. There is a horizontal movement of about 2 inches, and at the same time a vertical displacement of about 1 inch caused by a hammer that bounces the sieves up and down. Fifty shakes were found to be sufficient to sift a sample (see p. 437).

The soil aggregates have irregular shapes, yet they are compared as if they had regular shapes. Since their exact dimensions are not known, the calculation of the surface cannot be made in definite units, but only in relative terms, and so the comparison of surfaces on all the fractions of the sample is called "relative surface" and is expressed in nondimensional units.

In using the relative-surface values as here calculated, two assumptions are made: (1) that aggregates within the same sample of soil have the same volume weight; $(2)$ that the aggregates are cubes.

The value is calculated on the actual size of the sieve opening, which is the minimum size of particles in any size range, except for the fraction which passes through the finest sieve. Here an arbitrary value of one-half that of the finest sieve is used. These minimum values are proportional to the mean values for the size ranges and hence will not affect the ratio for the various sieve openings.

Since the same set of sieves was used for all of the sieve analyses, the value is a constant for any one fraction. The values for these fractions are as follows : through $3 / 128$ inch, $416.0 ; 3 / 128$ inch, $208.0 ; 3 / 64$ inch, 104 ; $3 / 32$ inch, 52 ; $3 / 16$ inch, $26 ; 3 / 8$ inch, $13.0 ; 3 / 4$ inch, $6.5 ; 15 / 8$ inches, 3.0 ; $31 / 4$ inches, 1.56 ; and $47 / 8$ inches, 1.0 . 
The relative-surface values are obtained according to the following formula :

where :

$$
R S=\sum\left(\frac{O_{1}}{O_{1}} M_{1}+\frac{O_{1}}{O_{2}} M_{2}+\ldots \frac{O_{1}}{O_{n}} M_{\mathrm{n}}\right),
$$

$R S=$ relative surface

$O_{1}=$ sieve opening of the coarsest sieve

$\mathrm{O}_{2}=$ sieve opening of the next coarsest sieve

$M_{1}=$ per cent of sample retained on the coarsest sieve

$M_{2}=$ per cent of sample retained on the next coarsest sieve.

The finest fractions have such a great influence on the values for relative surface that small differences in the percentage values for these finer fractions greatly affect this value, whereas large differences in the coarser fractions do not alter it very much.

Two soils with entirely different size distributions of aggregates may have very close relative-surface values; and, likewise, other soils that have very similar size distribution of particles may have relative-surface values that are not so close. If the percentage values for the three finest fractions are very much alike, the relative-surface values will not be greatly altered by a drastic change in the size distribution of the other seven fractions. In order to get a more complete picture of the changes that occur within any soil, both the figures for the size distribution of aggregates and the values for the relative surface are presented in form of tables, or, where the data on size distribution of aggregates are plotted as curves, the values for the relative surface are given in tabular form with the legend for the curves.

Plotting of Data on Graphs.-Many of the results here presented are plotted on graphs, which afford an easy way of making comparisons. The sieve openings are plotted as abscissas and summation percentages as ordinates. Summation percentages are used instead of the percentages on each sieve because the curves thus plotted are much easier to compare. When curves on the same graph are compared, the curve highest on the graph has the finest aggregates.

In the lower right-hand corner of each graph, the data for the four finest fractions are replotted on a larger scale: the scale for the abscissa is 10 times, and that for the ordinate 2 times, the respective scales on the main graph. 


\section{EVALUATION OF THE METHODS USED}

Effect of Sifting.-As the term is used in this discussion, a "soil aggregate" is composed of a number of individual soil particles that form a mass sufficiently stable to act as an individual unit.

Many of the clods had rather large cracks as the sample was placed on the large sieve. In most cases, the sifting manipulation was severe enough to break the clods apart at the cracks into aggregate units, but not severe enough to break up uncracked units. Careful observations of the clods on each sieve revealed that very few of them showed any cracks, yet their surfaces did not show fresh breaks, which was taken to indicate that very few aggregate units were broken in this process.

The amount of shaking will obviously affect the results : if inadequate, the sample will not be completely separated ; if too prolonged, the aggregates will be broken or worn down.

The data recorded in table 1 show two tests on Sacramento adobe clay with the Ro-tap shaker. The samples were shaken 50 times in the usual manner and the weight on each sieve recorded. The material was reassembled and the process repeated, this time with 200 shakings. The data were again recorded and the process repeated several times, with 250 shakings at each repetition thereafter, until 1,500 in all had been given the samples.

The percentage on the intermediate and finer sieves $(3 / 16,3 / 32,3 / 64$, and $3 / 128$ inch) did not change very much. The two coarsest sieves lost some material, and the solid pan gained a little by each successive series of shakings. These results indicate that although there is some wearing down of aggregates by shaking, it is more a case of grinding off corners than breaking down aggregates. A careful examination of the aggregates at the end of this prolonged shaking showed that, especially on the three coarsest sieves, they are well rounded, having almost the appearance of water-worn gravel. These data clearly show that the aggregates are sufficiently stable to be measured in this manner, and that 50 shakes of the Ro-tap are enough to separate the sample properly into the varioussized units.

Variability of Samples.-A certain amount of variability in the samples is to be expected, so that no one determination will convey a true picture of the state of aggregation of any soil. An average of several determinations will more accurately describe this condition, and all of the data presented are averages of four or more replicate samples.

Table 2 shows differences between 8 individual samples on each of three different sets taken in an orchard on Yolo loam as the field was 
being cultivated. The first set was taken before any tillage operation, the second after the same strip had been cultivated in one direction with a heavy disk harrow to a depth of 4 inches, and the third after it had been cross-cultivated with the same implement at right angles to the first operation. The cultivations were made on the same day, within a few hours

TABLE 1

Percentage Distribution of Soll Aggregates after Various Numbers of SHakings IN the Ro-Tap Shaker

\begin{tabular}{|c|c|c|c|c|c|c|c|c|}
\hline \multirow{2}{*}{$\begin{array}{l}\text { Number } \\
\text { of } \\
\text { shakings }\end{array}$} & \multicolumn{7}{|c|}{ Sieve opening } & \multirow{2}{*}{ Total } \\
\hline & \begin{tabular}{|} 
Through \\
$3 / 128$ inch
\end{tabular} & $\begin{array}{l}3 / 128 \\
\text { inch }\end{array}$ & $\begin{array}{l}3 / 64 \\
\text { inch }\end{array}$ & $\begin{array}{l}3 / 32 \\
\text { inch }\end{array}$ & $\begin{array}{l}3 / 16 \\
\text { inch }\end{array}$ & $\begin{array}{l}3 / 8 \\
\text { inch }\end{array}$ & $\begin{array}{c}3 / 4 \\
\text { inch }\end{array}$ & \\
\hline \multicolumn{9}{|c|}{ First test } \\
\hline 50. & 15.1 & 13.0 & 18.1 & 17.5 & 16.5 & 16.7 & 2.9 & 99.8 \\
\hline 250 .. & 16.8 & 13.5 & 18.7 & 17.3 & 16.5 & 14.0 & 2.7 & 99.5 \\
\hline 500. & 17.5 & 13.9 & 19.2 & 17.5 & 16.0 & 13.7 & 1.8 & 99.6 \\
\hline 750 . & 18.1 & 14.0 & 19.2 & 17.9 & 16.0 & 12.5 & 1.8 & 99.5 \\
\hline 1,000 . & 18.6 & 14.1 & 19.6 & 17.9 & 15.8 & 11.7 & 1.8 & 99.5 \\
\hline $1,250 \ldots$ & 18.9 & 14.3 & 19.6 & 18.0 & 15.7 & 11.2 & 1.8 & 99.5 \\
\hline 1,500 . & 19.4 & 14.3 & 19.7 & 18.0 & 15.5 & 12.0 & 0.8 & 99.7 \\
\hline \multicolumn{9}{|c|}{ Second test } \\
\hline 50. & 15.8 & 12.3 & 16.9 & 16.0 & 16.4 & 19.6 & 2.9 & 99.9 \\
\hline 250 . & 17.5 & 12.8 & 17.1 & 16.3 & 15.8 & 17.6 & 1.9 & 100.0 \\
\hline $500 \ldots$ & 18.0 & 12.8 & 17.4 & 16.5 & 15.5 & 17.4 & 1.9 & 99.5 \\
\hline 750. & 18.7 & 12.8 & 17.4 & 16.5 & 15.8 & 16.7 & 1.7 & 99.5 \\
\hline 1,000 . & 19.2 & 13.1 & 17.4 & 16.6 & 15.3 & 16.2 & 1.0 & 98.8 \\
\hline 1,250 . & 19.5 & 13.2 & 17.4 & 16.8 & 15.6 & 15.1 & 1.0 & 98.6 \\
\hline $1,500$. & 20.1 & 13.1 & 17.6 & 16.9 & 15.5 & 14.4 & 1.0 & 98.6 \\
\hline
\end{tabular}

of each other, and all of the samples were taken within an area about 20 feet square.

Definite pulverizing effect is obtained by each tillage operation, yet there is considerable variation between individual samples for each treatment. There is usually a greater variability in the coarser fractions than in the intermediate and finer fractions. Some variability may be ascribed to the method of making the determinations, but much more of it is due to the natural heterogeneity of the soil, so that an average of a number of replicate samples for the same treatment is the only safe way of making comparisons between different cultural treatments.

Comparison of Moist and Air-dry Sifting.-Keen (12) and Hoffman ${ }^{5}$ sifted their samples as they were taken from the field. In the present study, because comparisons were to be made between samples taken from

${ }^{5}$ Hoffman, A. H. Unpublished manuseript. 
fields under variable conditions of texture and moisture, and also at different seasons, it was desirable to bring the samples to moisture conditions as nearly comparable as possible. The air-dry state is most con-

TABLE 2

Variability in Percentage Distribution of Soll Aggregates in Individual SAMPLES OF YOLO LOAM

\begin{tabular}{|c|c|c|c|c|c|c|c|c|c|c|c|}
\hline \multirow{2}{*}{$\begin{array}{c}\text { Sample } \\
\text { No. }\end{array}$} & \multicolumn{10}{|c|}{ Sieve opening } & \multirow{2}{*}{$\begin{array}{l}\text { Rela- } \\
\text { tive } \\
\text { surface }\end{array}$} \\
\hline & $\begin{array}{l}\text { Through } \\
\text { 3/128 } \\
\text { inch }\end{array}$ & $\begin{array}{c}3 / 128 \\
\text { inch }\end{array}$ & $\begin{array}{l}3 / 64 \\
\text { inch }\end{array}$ & $\begin{array}{l}3 / 32 \\
\text { inch }\end{array}$ & $\begin{array}{l}3 / 16 \\
\text { inch }\end{array}$ & $\begin{array}{c}3 / 8 \\
\text { inch }\end{array}$ & $\begin{array}{c}3 / 4 \\
\text { inch }\end{array}$ & $\begin{array}{c}15 / 8 \\
\text { inches }\end{array}$ & $\begin{array}{c}31 / 4 \\
\text { inches }\end{array}$ & $\begin{array}{c}47 / 8 \\
\text { inches }\end{array}$ & \\
\hline \multicolumn{12}{|c|}{ No cultivation } \\
\hline 1 & 5.0 & 1.8 & 2.5 & 3.7 & 5.5 & 9.1 & 14.2 & 24.1 & 24.8 & 9.5 & 3,380 \\
\hline 2 & 3.9 & 1.4 & 2.2 & 3.3 & 5.1 & 8.2 & 12.5 & 18.4 & 10.6 & 34.3 & 2,741 \\
\hline 3 & 4.8 & 1.7 & 2.5 & 3.9 & 5.3 & 8.0 & 12.0 & 17.4 & 27.5 & 16.5 & 3,243 \\
\hline 4 & 4.2 & 1.3 & 2.0 & 3.4 & 6.0 & 10.9 & 18.4 & 20.2 & 21.2 & 12.4 & 2,935 \\
\hline 5 & 5.8 & 1.7 & 2.4 & 3.7 & 5.6 & 9.6 & 11.4 & 31.7 & 28.2 & 0.0 & 3,694 \\
\hline 6 & 7.4 & 1.9 & 2.8 & 4.3 & 6.5 & 10.6 & 14.6 & 30.7 & 12.1 & 8.9 & 4,513 \\
\hline 7 & 6.6 & 1.9 & 2.9 & 4.5 & 6.8 & 10.3 & 13.1 & 28.1 & 17.8 & 8.2 & 4,191 \\
\hline 8 & 4.5 & 1.4 & 2.0 & 3.2 & 4.9 & 7.4 & 11.9 & 16.5 & 19.0 & 29.3 & 2,947 \\
\hline Av. & 5.3 & 1.6 & 2.4 & 3.8 & 5.7 & 9.3 & 13.5 & 23.4 & 20.2 & 14.9 & 3,460 \\
\hline \multicolumn{12}{|c|}{ Cultivated one way } \\
\hline 9 & 10.9 & 3.3 & 4.7 & 6.8 & 9.2 & 13.0 & 15.8 & 20.7 & 15.5 & 0.0 & 6,656 \\
\hline 10 & 9.6 & 3.2 & 4.7 & 7.5 & 10.3 & 15.9 & 22.6 & 26.4 & 0.0 & 0.0 & 6,242 \\
\hline 11 & 14.3 & 4.1 & 5.1 & 8.0 & 14.3 & 18.2 & 20.2 & 11.6 & 4.2 & 0.0 & 8,570 \\
\hline 12 & 12.1 & 3.7 & 5.3 & 7.4 & 11.1 & 15.5 & 18.2 & 16.1 & 10.3 & 0.0 & 7,390 \\
\hline 13 & 12.6 & 3.0 & 4.3 & 6.7 & 9.9 & 13.7 & 17.8 & 27.9 & 4.2 & 0.0 & 7,290 \\
\hline 14 & 12.7 & 3.4 & 4.3 & 6.0 & 8.7 & 12.1 & 15.9 & 14.0 & 22.8 & 0.0 & 7,300 \\
\hline 15 & 10.2 & 3.2 & 5.1 & 8.2 & 11.4 & 15.2 & 19.3 & 18.5 & 9.0 & 0.0 & 6,551 \\
\hline 16 & 11.3 & 2.9 & 4.4 & 7.0 & 11.2 & 15.7 & 26.1 & 22.2 & 0.0 & 0.0 & 6,857 \\
\hline Av. & 11.7 & 3.4 & 4.7 & 7.2 & 10.8 & 14.9 & 19.5 & 19.7 & 8.3 & 0.0 & 7,113 \\
\hline \multicolumn{12}{|c|}{ Cultivated 2 ways } \\
\hline 17 & 17.7 & 5.6 & 8.1 & 11.7 & 14.7 & 17.9 & 14.6 & 9.8 & 0.0 & 0.0 & 10,724 \\
\hline 18 & 12.7 & 4.6 & 6.7 & 10.0 & 13.6 & 17.8 & 22.4 & 13.2 & 0.0 & 0.0 & 8,285 \\
\hline 19 & 16.9 & 5.4 & 7.2 & 10.1 & 13.6 & 17.4 & 17.8 & 11.6 & 0.0 & 0.0 & 10,158 \\
\hline 20 & 14.2 & 4.8 & 6.8 & 9.0 & 13.0 & 17.1 & 25.4 & 9.5 & 0.0 & 0.0 & 8,829 \\
\hline 21 & 23.1 & 5.8 & 7.3 & 9.6 & 11.7 & 13.5 & 13.7 & 12.9 & 2.2 & 0.0 & 12,678 \\
\hline 22 & 15.3 & 5.7 & 8.3 & 12.5 & 17.9 & 20.9 & 15.4 & 3.7 & 0.0 & 0.0 & 9,986 \\
\hline 23 & 14.5 & 5.9 & 8.2 & 11.0 & 13.6 & 16.0 & 15.1 & 12.2 & 2.5 & 0.0 & 9,393 \\
\hline 24 & 18.6 & 7.0 & 8.9 & 11.3 & 13.5 & 16.2 & 15.8 & 4.7 & 4.1 & 0.0 & 11,393 \\
\hline Av. & 16.6 & 5.6 & 7.7 & 10.7 & 14.0 & 17.1 & 17.5 & 9.7 & 1.1 & 0.0 & 10,203 \\
\hline
\end{tabular}

venient, even though this necessitates storing the samples while drying.

A few tests were made to compare samples sifted at field moisture content and under air-dry conditions. The data (table 3) for samples from fields of Yolo loam and of Yolo silt loam are presented to show the 
differences in samples taken at the same time, one set sifted immediately after sampling, and the other air-dried before sifting. Replicate samples agreed well when sifted moist as well as when sifted in the air-dry state. There were marked differences in the size distribution under these two systems of handling the samples. The amounts both of very coarse material and of fine material were always greater when sifted in the air-dry condition.

At field moisture content, the larger aggregates seem to have been weak enough to be broken by the amount of agitation necessary for com-

TABLE 3

Percentage Distribution of Size Aggregates Sifted Air-dry and at Field Moisture Content

\begin{tabular}{|c|c|c|c|c|c|c|c|c|c|c|c|c|}
\hline \multirow{2}{*}{ Soil and plot No. } & \multirow{2}{*}{$\begin{array}{c}\text { Per } \\
\text { cent } \\
\text { of } \\
\text { water }\end{array}$} & \multicolumn{10}{|c|}{ Sieve opening } & \multirow{2}{*}{$\begin{array}{c}\text { Rela- } \\
\text { tive } \\
\text { sur- } \\
\text { face }\end{array}$} \\
\hline & & $\begin{array}{c}\text { Through } \\
3 / 128 \\
\text { inch }\end{array}$ & $\begin{array}{l}3 / 128 \\
\text { inch }\end{array}$ & $\begin{array}{l}3 / 64 \\
\text { inch }\end{array}$ & $\begin{array}{l}3 / 32 \\
\text { inch }\end{array}$ & $\begin{array}{l}3 / 16 \\
\text { inch }\end{array}$ & $\begin{array}{c}3 / 8 \\
\text { inch }\end{array}$ & $\begin{array}{c}3 / 4 \\
\text { inch }\end{array}$ & $\begin{array}{c}15 / 8 \\
\text { inches }\end{array}$ & inches & $\begin{array}{c}47 / 8 \\
\text { inche }\end{array}$ & \\
\hline \multirow{2}{*}{$\begin{array}{l}\text { Yolo loam } \\
\text { Plot } 1 . .\end{array}$} & $|3.42|$ & 5.4 & 3.5 & 4.6 & 6.2 & 8.5 & 12.2 & 15.0 & 23.0 & 17.6 & 4.3 & 4,362 \\
\hline & 20.9 & 1.6 & 7.3 & 12.2 & 11.4 & 13.9 & 17.3 & 18.1 & 13.8 & 4.9 & 0.0 & 4,791 \\
\hline \multirow{2}{*}{ Plot 2.} & 3.06 & 6.2 & 3.7 & 4.8 & 6.2 & 8.3 & 11.3 & 14.3 & 23.5 & 21.6 & 0.0 & 4,718 \\
\hline & 20.1 & 2.0 & 7.3 & 11.6 & 10.7 & 13.0 & 16.4 & 17.2 & 19.8 & 2.0 & 0.0 & 4,805 \\
\hline \multirow{2}{*}{ Plot 3.} & $\int 3.30$ & 3.5 & 2.0 & 3.0 & 4.1 & 6.0 & 9.7 & 15.6 & 25.1 & 26.2 & 4.7 & 2,936 \\
\hline & 21.5 & 0.3 & 3.3 & 9.5 & 9.4 & 11.5 & 15.9 & 18.3 & 25.5 & 6.3 & 0.0 & 2,993 \\
\hline \multirow[t]{2}{*}{ Yolo silt loam } & 3.10 & 6.5 & 2.5 & 3.0 & 4.3 & 6.5 & 10.1 & 14.1 & 27.3 & 19.9 & 6.2 & 4,259 \\
\hline & 21.9 & 4.2 & 6.6 & 8.7 & 9.0 & 11.7 & 15.8 & 19.9 & 20.5 & 3.3 & 0.0 & 5,202 \\
\hline \multirow[t]{2}{*}{ Plot 2.} & $\{3.25$ & 6.8 & 2.6 & 3.2 & 4.4 & 6.3 & 9.6 & 14.6 & 25.9 & 14.4 & 12.3 & 4,436 \\
\hline & $21.7\}$ & 3.4 & 8.5 & 11.3 & 11.0 & 13.4 & 17.6 & 19.3 & 14.1 & 1.4 & 0.0 & 4,632 \\
\hline \multirow[t]{2}{*}{ Plot 3.} & 3.18 & 3.8 & 2.3 & 3.1 & 4.4 & 6.6 & 10.5 & 15.4 & 24.3 & 23.7 & 6.0 & 3,124 \\
\hline & 21.7 & 0.8 & 5.3 & 7.5 & 8.4 & 11.2 & 14.4 & 15.8 & 26.9 & 9.7 & 0.0 & 3,350 \\
\hline
\end{tabular}

plete separation with this apparatus. On the other hand, there was less material fine enough to pass through the finest sieve. The moisture films undoubtedly held the dust particles together in aggregates sufficiently stable to prevent their passing through the finest sieve on the Ro-tap shaker. In two respects, therefore, size distribution of aggregates as found by sifting the samples at their field moisture content is obviously different from that of the samples when taken from the field.

With the air-dry samples, on the contrary, the stability previously demonstrated (p. 437) for the air-dry aggregates indicates that the size distribution as found by sifting was essentially the same as that before sifting. It may be argued that there is a possibility for change in the size 
of the aggregates as the samples dry out, but this phase was not investigated.

The relative-surface values under the two different sets of conditions are not greatly different.

For comparison of the degree of wetness of the various samples, the ratio of the moisture content to the moisture equivalent at the time of sifting is given in table 4 . These soils were all sampled the same length of time after a series of irrigations, and were very close in their degree of wetness and actual moisture content.

TABLE 4

Ratio of Percentage of Water at Field Capacity to Moisture Equivalent in Yolo Loam and Yolo Silt LoAM

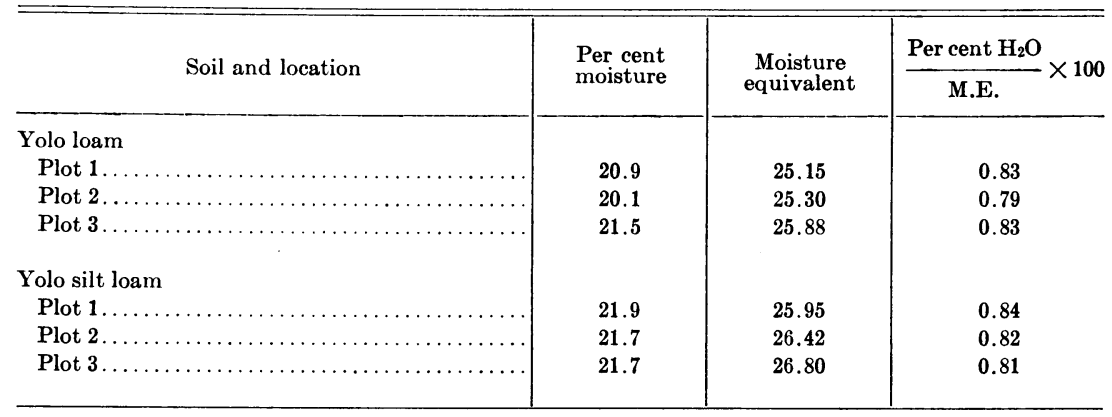

\section{EFFECT OF TILLAGE ON MACROSTRUCTURE}

Orchards.-Permanent crops, such as orchards and vineyards, are usually subjected to tillage operations for the purposes of turning under covercrops or destroying weeds. Usually this is done with disks of some type, either single or double, and the depth of penetration of the implement is rather shallow, 3 to 6 inches being the most common. In the present study, the implement was a heavy single-disk harrow, operated at depths of 4 to 5 inches. The second cultivation, when given, was at right angles to the first.

Table 5 gives the data for orchards on the Yolo series. In all cases, each tillage operation had a distinct pulverizing effect.

Yolo loam was sampled in three locations (table 5, plots 100, 200, and 300 ), and considerable variation was found in the size distribution at each location before any tillage operation was performed. In each case, there was a distinct pulverizing effect by each operation, but the intensity of this effect was variable.

The two locations on the Yolo clay loam (plots 400 and 500) were not 
so variable before tillage, and the pulverizing effect of the tillage was also a little more uniform.

The soils with the coarser textures were less aggregated than those of the finer textures. Before tillage, Yolo fine sandy loam (plot 000) showed a much finer condition of aggregates than the other two soils. It had rela-

TABIJE 5

Percentage Distribution of Soll Aggregates from Difrerent Locations AND SOIL TYPES IN AN ORCHARD

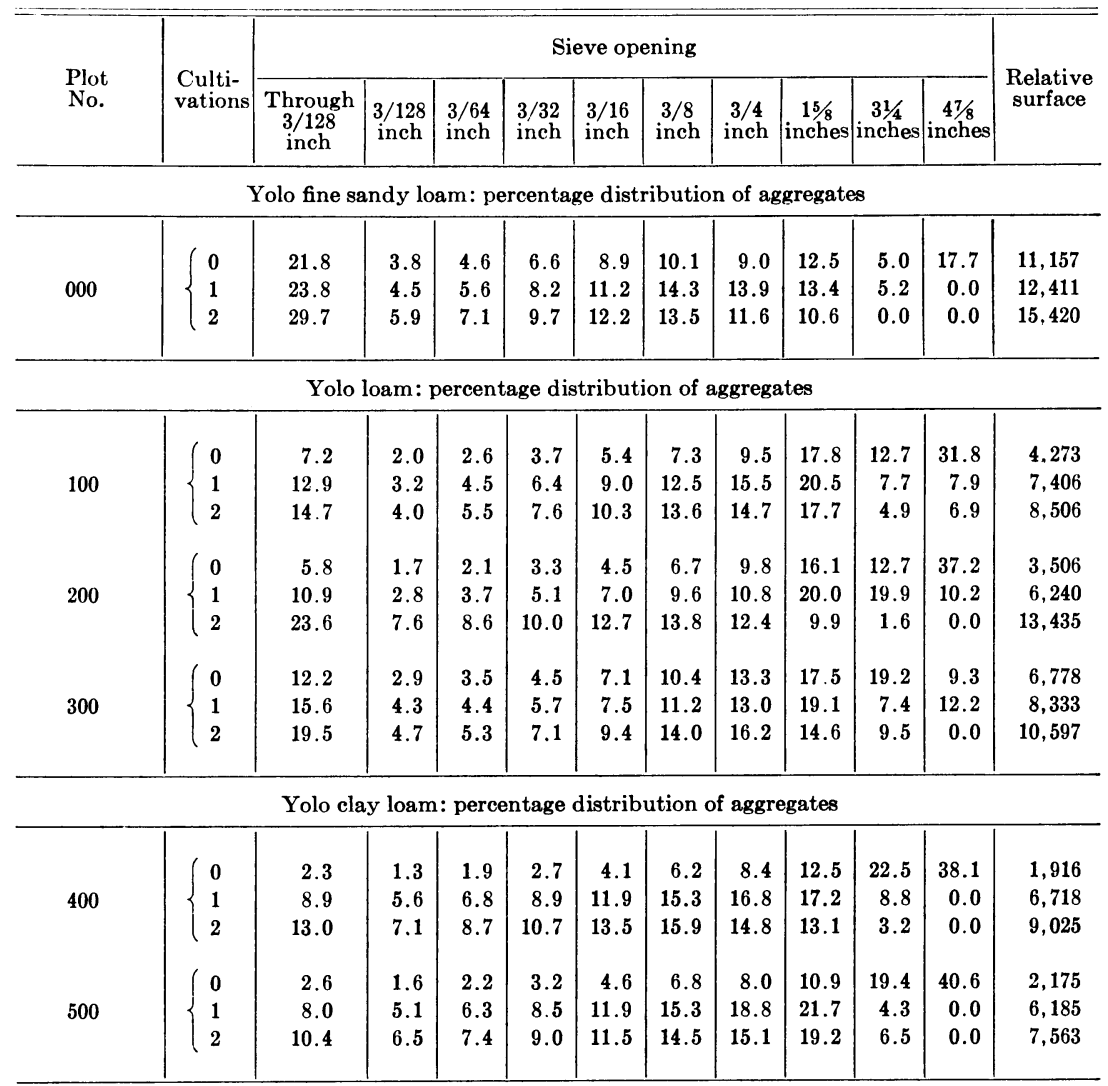

tive-surface values two or three times as great as the loam and five or six times as great as the clay loam.

Table 6 shows the results of two seasons' studies on tillage in an orchard on Denverton adobe clay. During the 1933 season, there was no noticeable pulverizing effect due to the tillage operations, whereas there was a slight pulverizing effect after the second cultivation in the 1934 season. The soil was in a more cloddy condition in 1934 than in 1935. 
Despite its heavy texture, this soil showed a good granular structure. The soil cracks into large adobe blocks on drying out, but these large blocks have numerous secondary cracks that break the soil into rather small irregular-shaped clods that are themselves rather firm; hence, the tillage operation did not have a very strong pulverizing effect.

In order to compare more closely the size distribution of aggregates after the various treatments, the data from one set of samples from Yolo loam and one set from the Denverton adobe clay are plotted on graphs.

TABLE 6

Percentage Distribution of Size Aggregates before and after Tillage Operations in an Orchard on Denverton Adobe Clay, 1933 and 1934

\begin{tabular}{|c|c|c|c|c|c|c|c|c|c|c|c|c|}
\hline \multirow{2}{*}{ Year } & \multirow{2}{*}{$\begin{array}{l}\text { Culti- } \\
\text { vations }\end{array}$} & \multicolumn{10}{|c|}{ Sieve opening } & \multirow{2}{*}{$\begin{array}{l}\text { Relative } \\
\text { surface }\end{array}$} \\
\hline & & $\begin{array}{c}\text { Through } \\
3 / 128 \\
\text { inch } \\
\end{array}$ & $\begin{array}{l}3 / 128 \\
\text { inch }\end{array}$ & $\begin{array}{l}3 / 64 \\
\text { inch }\end{array}$ & $\begin{array}{l}3 / 32 \\
\text { inch }\end{array}$ & $\begin{array}{l}3 / 16 \\
\text { inch }\end{array}$ & $\begin{array}{c}3 / 8 \\
\text { inch }\end{array}$ & $\begin{array}{c}3 / 4 \\
\text { inch }\end{array}$ & $\begin{array}{c}15 / 8 \\
\text { inches }\end{array}$ & $\begin{array}{c}31 / 4 \\
\text { inches }\end{array}$ & $\begin{array}{c}37 / 8 \\
\text { inches }\end{array}$ & \\
\hline \multirow{4}{*}{1933} & 0 & 13.9 & 13.3 & 15.2 & 14.6 & 14.4 & 12.3 & 7.7 & 7.3 & 1.4 & 0.0 & 11,510 \\
\hline & 1 & 15.5 & 14.3 & 16.0 & 15.0 & 15.0 & 12.9 & 7.1 & 4.2 & 0.0 & 0.0 & 12,483 \\
\hline & $2^{*}$ & 14.7 & 12.3 & 13.2 & 12.8 & 13.7 & 14.6 & 11.5 & 7.2 & 0.0 & 0.0 & 11,363 \\
\hline & $\begin{array}{l}\text { After } \\
\text { rain }\end{array}$ & 13.8 & 12.6 & 14.0 & 13.6 & 14.6 & 14.3 & 11.6 & 5.6 & 0.0 & 0.0 & 11,159 \\
\hline \multirow{3}{*}{1934} & 0 & 7.0 & 8.9 & 11.0 & 10.2 & 13.4 & 14.8 & 12.1 & 25.1 & 0.0 & 0.0 & 7,108 \\
\hline & 1 & 7.3 & 9.2 & 12.1 & 12.4 & 14.1 & 16.3 & 28.5 & 0.0 & 0.0 & 0.0 & 7,622 \\
\hline & $2^{*}$ & 10.7 & 11.8 & 15.4 & 13.9 & 14.1 & 15.6 & 18.5 & 0.0 & 0.0 & 0.0 & 9,895 \\
\hline
\end{tabular}

* Second cultivation at right angles to first.

Figure 1 gives the data for plot 300 on Yolo loam and shows the distinct pulverizing effect of each cultivation. The curves have similar shapes. The differences are also manifest in the relative-surface values.

Figure 2 shows the curves for the 1933 samplings on Denverton adobe clay. The size distribution of aggregates in these samples was not greatly altered by the cultural treatments. These curves occur much higher on the graph than those of the Yolo loam, which shows them to have finer aggregates. The curves are very close together and of similar shape. Curve $B$, after cultivation in one direction, is slightly higher than the other curves on this graph. This difference is also manifest in the relativesurface values. The other three curves cross each other a number of times and are very close together throughout the entire range of the curve. Their relative-surface values are also very close.

Seedbed for Beans.-In 1933 and 1934 a number of studies were carried out on a private farm in the vicinity of Davis, California. The studies were made on the size distribution of aggregates after different tillage operations in preparing seedbeds. This farm is composed mainly of soils of the Yolo series, ranging in texture from fine sandy loam to clay loam, but there is also a body of Capay adobe clay on this farm. 


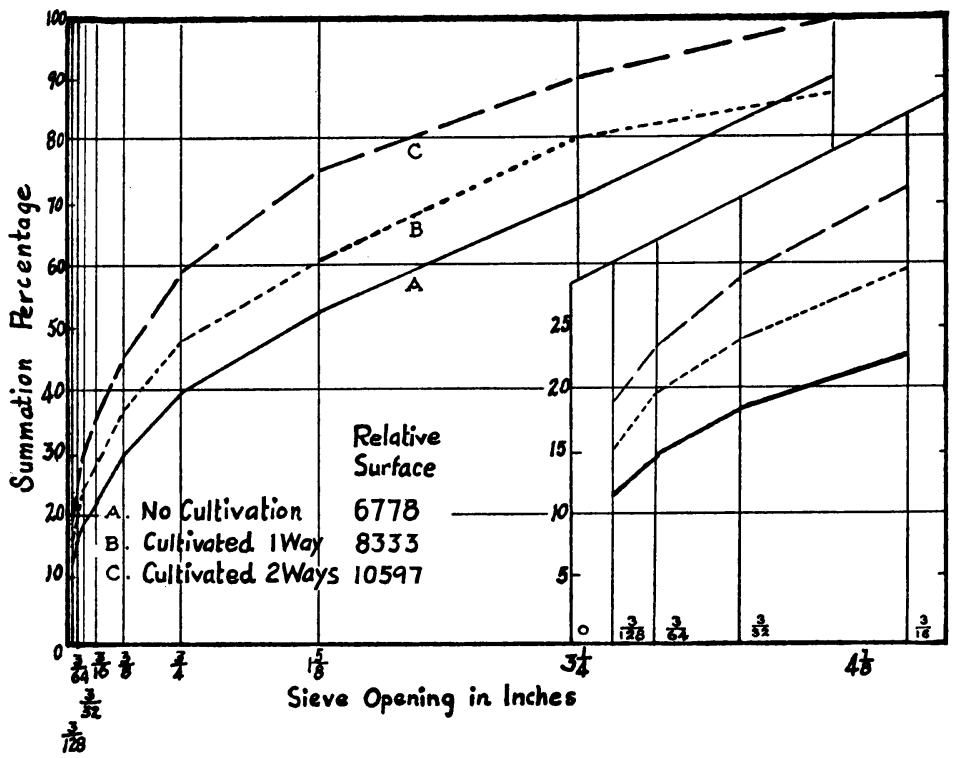

Fig. 1.-Size distribution of aggregates before and after tillage operations in an orchard (plot 300) on Yolo loam soil, 1933.

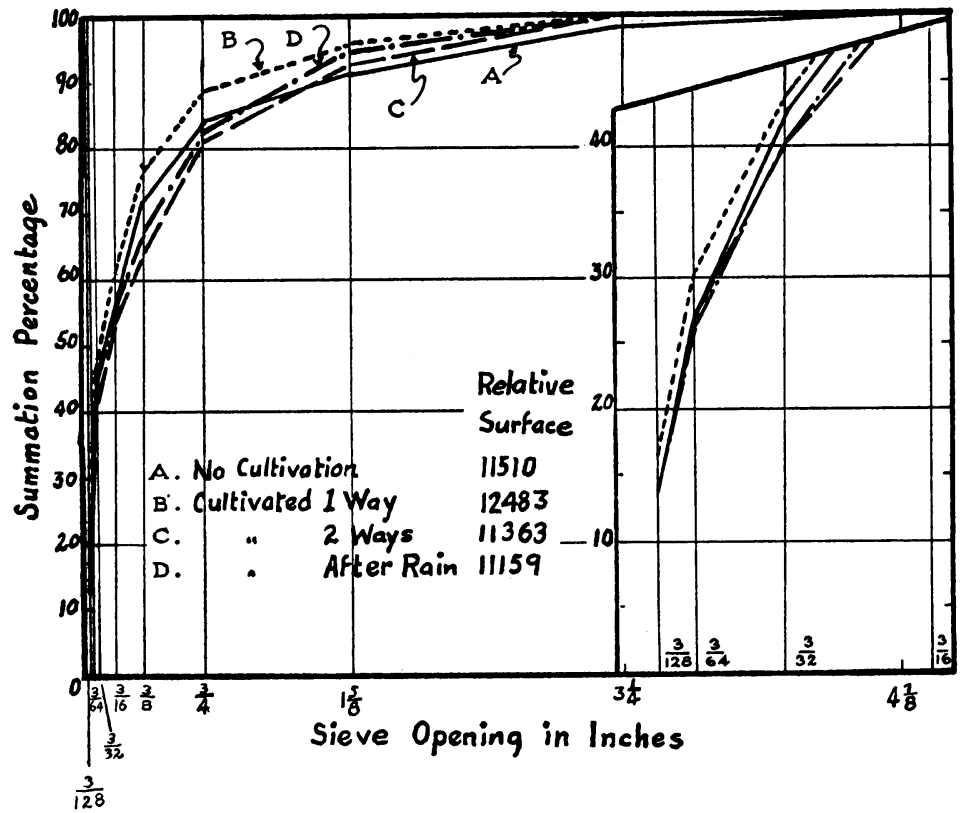

Fig. 2.- Size distribution of aggregates before and after tillage operations in an orchard on Denverton adobe clay, 1933. 
The farm had been used for dry-land grain for a good many years. For four or five years previous to these investigations, the entire farm had been in sod and pastured to sheep.

In 1934 a field of considerable size was planted to beans. Two areas were selected for the investigations on the preparation of the seedbed: one area was on Yolo clay loam and the other on Capay adobe clay.

The bean field was worked as a unit, and the treatments on the whole field were the same. These were briefly as follows: The field was plowed in a fairly dry condition, to a depth of 6 inches. Some leveling was done next by use of a heavy float and a large scraper. After this, the field was preirrigated, permitted to dry at the surface for nearly a month, then harrowed with a spring-tooth harrow, and finally rolled with a cultipacker before seeding. The leveling work on this field did not necessitate the moving of very much soil except for small localized areas. No soil was moved to or from the areas in either sampling location.

All of the data for the studies of preparation of seedbed on this farm are plotted in graphs. Figure 3 shows the results of the treatments on Yolo clay loam and figure 4 shows those for Capay adobe clay. On the Yolo clay loam, the plowing had only a very slight pulverizing effect, but the same treatment had a very definite pulverizing effect on the Capay adobe clay. On both plots, the leveling operations had a very strong pulverizing effect, and the plots were in their most finely pulverized state after this treatment. After the preirrigation and subsequent drying period, both plots were far more cloddy than they had been before they had received any cultural treatment. On both plots, the harrowing with a spring-tooth harrow and rolling with a cultipacker had some pulverizing effect. The curves for the data on the Yolo clay loam (fig. 3) are of very similar shape. The three curves $A, B$, and $F$ are close together, yet the corresponding relative-surface values are 4,940, 5,348, and 5,648, respectively. As previously noted, small changes in the percentage of the finer fractions cause large changes in these values. Curve $F$ falls between curves $A$ and $B$ throughout most of its length, but the percentage of very fine fractions is higher in $F$, as shown on the enlargement at the lower right-hand corner of figure 3 .

The similarity of curves $A$ and $F$ indicates that, for this soil, the size distribution of aggregates was practically no different when the field was seeded than it had been before plowing. The actual physical condition of the field, however, was greatly altered. The soil was dry and compact and in a fairly heavy sod before plowing. As the field was finally fitted before seeding, it was loose and friable and the sod had all been broken up. Unfortunately no volume-weight measurements were taken this season. 


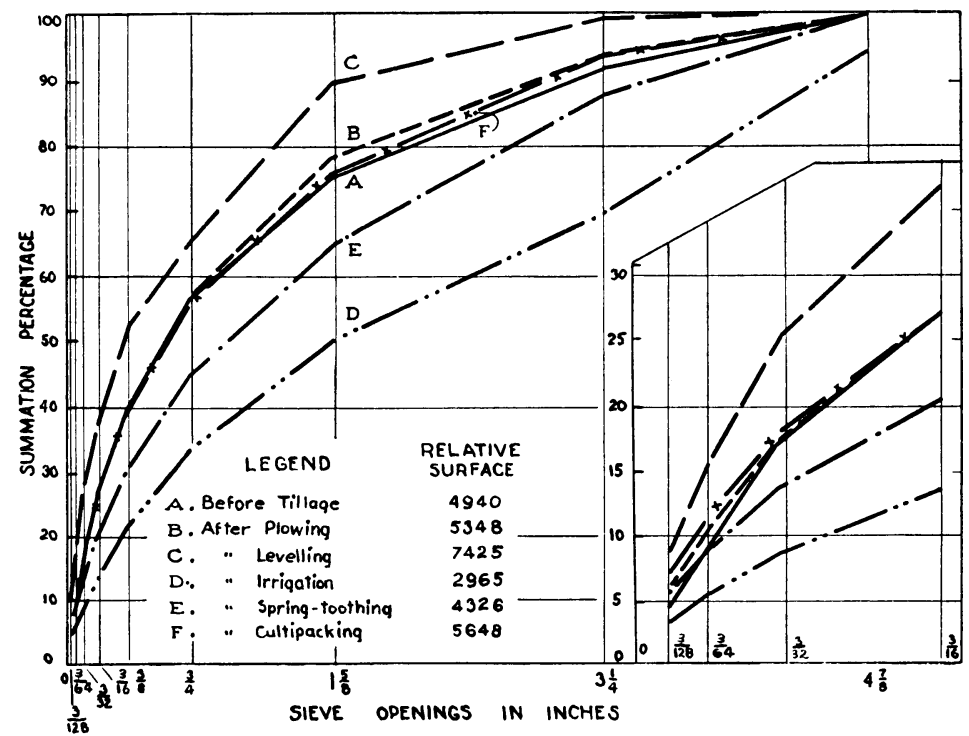

Fig. 3.- Size distribution of aggregates before and after tillage operations in preparation of seedbed for beans on Yolo clay loam, 1934.

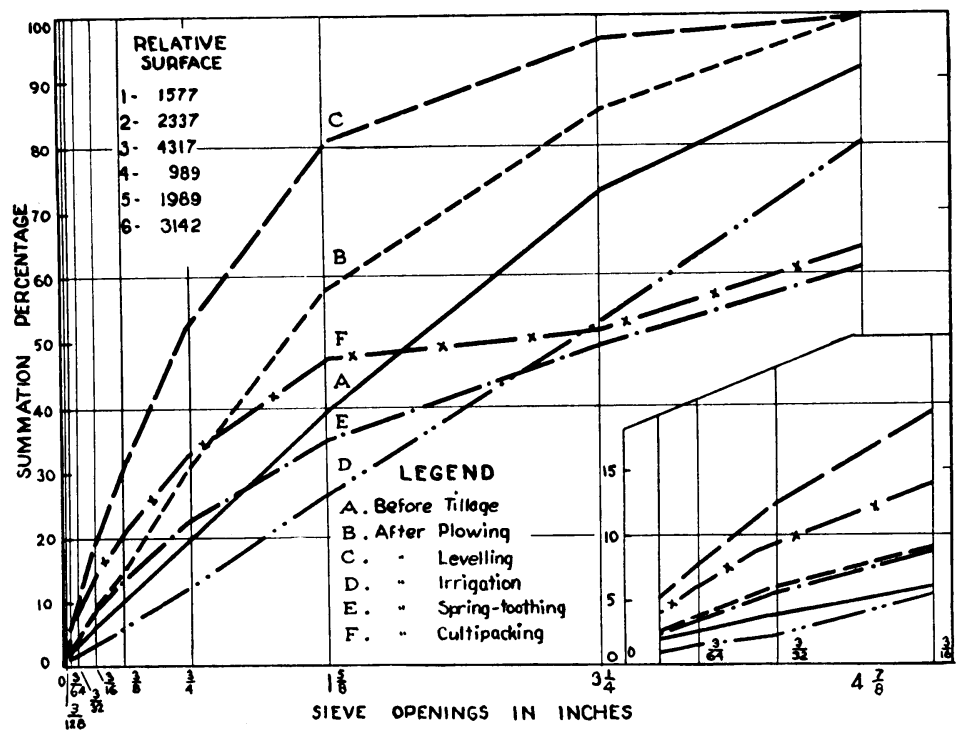

Fig. 4.-Size distribution of aggregates before and after tillage operations in preparation of seedbed for beans on Capay adobe clay, 1934 . 
The curves in figure 4 for Capay adobe clay are spread wider apart than those in figure 3. Curves $E$ and $F$ in this figure do not have the same general shape as the others. The field was permitted to dry for several weeks after irrigation. The Capay soils have very sluggish drainage, and water stood on this area several days longer than on the Yolo clay loam. As the field dried out after the water disappeared from the surface, a definite crust about 2 inches thick was formed; below this, the soil was very wet. The field was in this condition when the spring-tooth harrowing and cultipacking were done. In both instances, samples were taken to 4-inch depths. Harrowing increased the amount of fine material over that of the sample before any tillage was done, but also increased the amount of coarse material. The drier soil at the surface was somewhat crumbled, but the pressure of the implement caused the very wet soil under the crust to be pressed together, and this dried out into very coarse lumps. The subsequent rolling with the cultipacker had a rather strong pulverizing effect on the crust but did not affect the lower portion of this layer. Here again, the strong influence of the finer fractions is clearly shown. Curve $A$ is above curve $E$ for most of its length but somewhat below the latter at the beginning; yet it has a relative-surface value of 1,577 as compared to that of 1,989 for curve $E$. Curve $F$ has a relativesurface value of 3,142 , which is just double that for curve $A$; yet it lies above curve $A$ for only about half its length and falls far below for the last half.

The size-distribution curves and relative-surface values show the Yolo clay loam to have much less cloddy structure than the Capay adobe clay.

Seedbed for Sugar Beets.-In 1935 on this same farm two fields were being prepared for sugar beets. The smaller field was nearly all Yolo clay loam; the larger field had two textural types, Yolo loam and Yolo fine sandy loam. Representative areas of each of the three types were selected, and samples were taken after each tillage operation. Volumeweight determinations were made as the samples were taken. The two fields were not worked simultaneously, and the treatments were not exactly alike. The areas of loam and fine sandy loam, however, were worked in one unit, and so these two types can be readily compared. The data for the loam texture are shown in figure 5 and those for the fine sandy loam in figure 6 .

On this field, the plowing was done with moldboard plows, and a small amount of leveling was done by a large, heavy, wooden float. The disking and harrowing were done in one operation with a spike-tooth harrow attached behind a double-disk harrow. After harrowing, the field was seeded and then rolled with a cultipacker. 


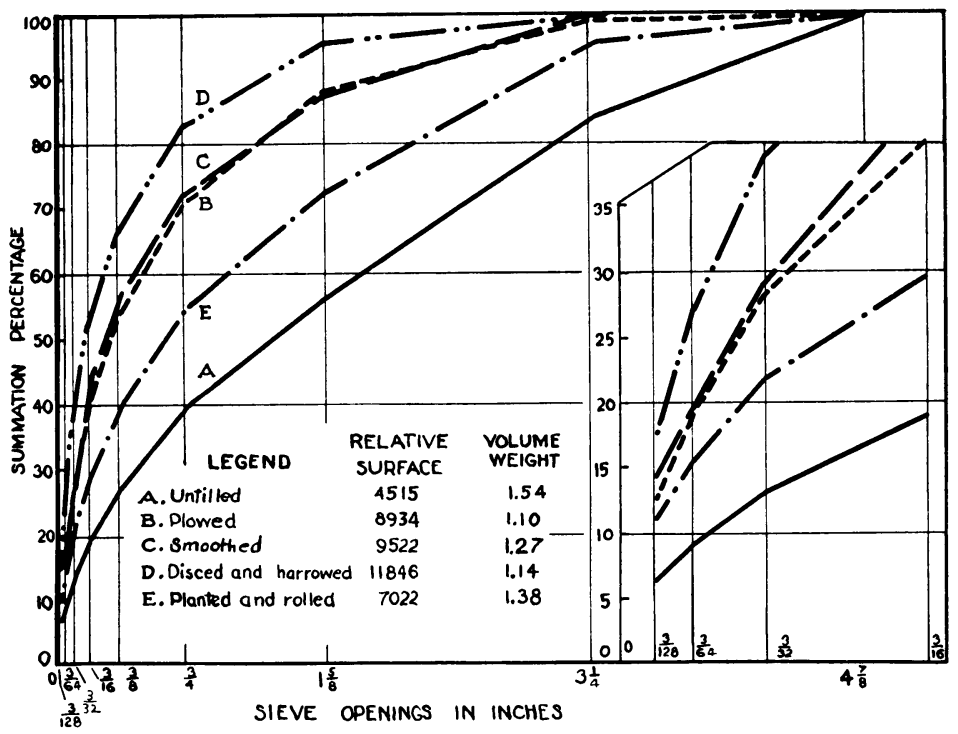

Fig. 5.-Size distribution of aggregates before and after tillage operations in preparation of seedbed for sugar beets on Yolo loam, 1935.

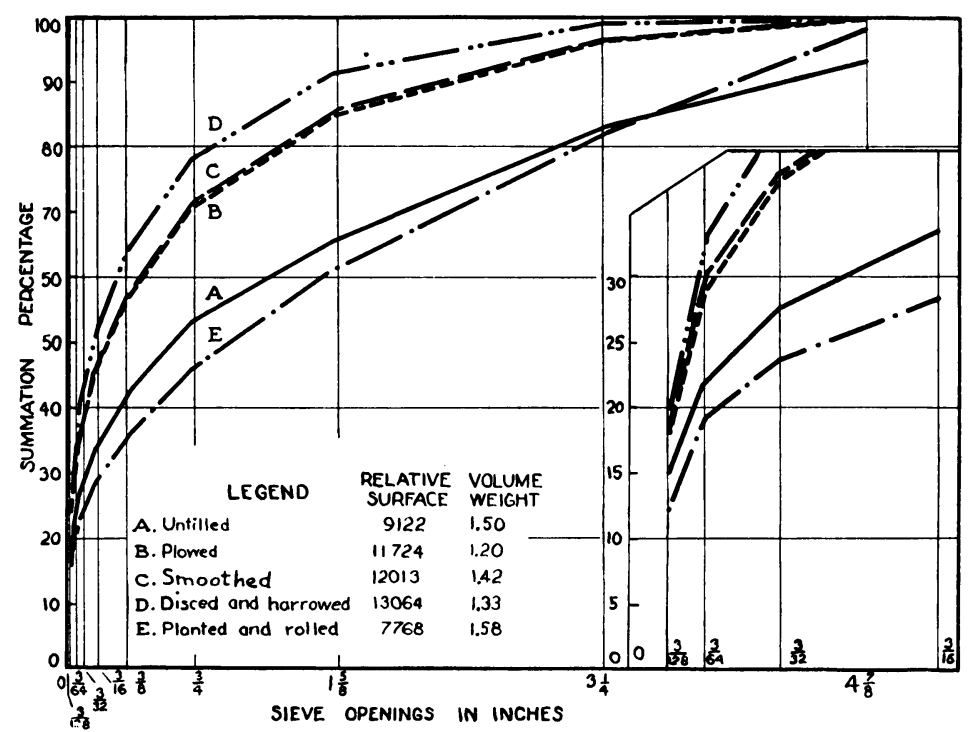

Fig. 6.-Size distribution of aggregates before and after tillage operations in preparation of seedbed for sugar beets on Yolo fine sandy loam, 1935. 
On both of these types, plowing had a very pronounced pulverizing effect and also a definite loosening effect. The curves for the plowing treatment lie above those for the soil before tilling in both cases, and there was a definite decrease in the volume weight of the soil : the Yolo loam decreased in volume weight from 1.54 to 1.10 and the fine sandy loam from 1.50 to 1.20 , after plowing.

Although, with both types, the relative-surface values were slightly higher after the use of the float, no appreciable change in the size distri-

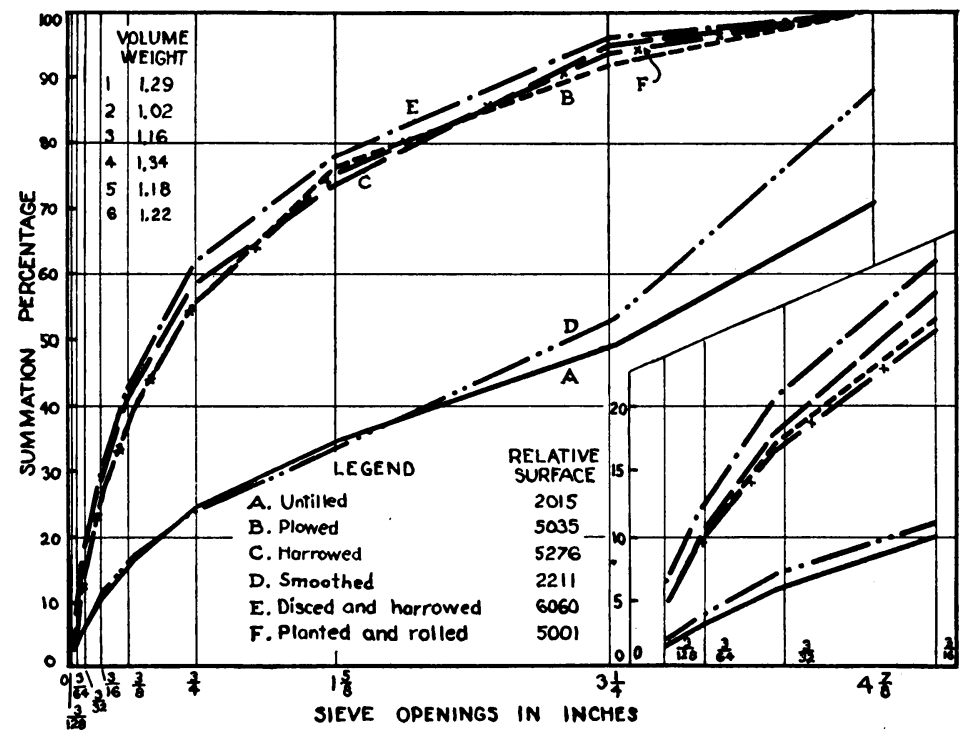

Fig. 7.-Size distribution of aggregates before and after tillage operations in preparation of seedbed for sugar beets on Yolo clay loam, 1935.

bution of aggregates occurred: curves $B$ and $C$ are almost identical throughout their length, both in figure 5 and in figure 6 . On the other hand, the use of the float had a very pronounced effect in compacting the soil, as shown by the increases in the volume weights. On both types, the harrowing had a decided pulverizing and loosening effect. Volume weight decreased very definitely : in the case of the Yolo loam, it was reduced almost to that after plowing.

The planting and rolling in both instances increased the cloddiness and the volume weights. On the loam texture, the soil was somewhat more pulverized than before plowing, and the volume weight somewhat less. On the fine sandy loam, however, the soil was a little more cloddy and a little more compact after the final operation than before any tillage was performed. 
The field of Yolo clay loam on the same farm, also being prepared for sowing sugar beets, was tilled a little later, and during the process there were a number of storms, which slightly altered the procedure on this field. Furthermore, this field was still in sod, whereas the other field on the loam and fine sandy loam types had been in a cultivated crop the year before. After plowing, this field was harrowed with a spike-tooth harrow to further break up the sod before it was worked with the float, so that this field had one more tillage operation than the other. The results on

TABLE 7

Moisture Condition of SoIls of the Yolo Series as Tillage Operations were Performed in Preparation of Seedbed for Sugar Beets, 1935

\begin{tabular}{|c|c|c|c|c|c|c|}
\hline \multirow[b]{2}{*}{ Treatment } & \multicolumn{2}{|c|}{$\begin{array}{l}\text { Yolo loam } \\
\text { (M.E., 20.13) }\end{array}$} & \multicolumn{2}{|c|}{$\begin{array}{l}\text { Yolo fine sandy loam } \\
\text { (M.E., 18.78) }\end{array}$} & \multicolumn{2}{|c|}{$\begin{array}{l}\text { Yolo clay loam } \\
\text { (M.E., 26.58) }\end{array}$} \\
\hline & $\begin{array}{l}\text { Per cent } \\
\mathrm{H}_{2} \mathrm{O}\end{array}$ & $\begin{array}{c}\text { Per cent } \\
\frac{\mathrm{H}_{2} \mathrm{O}}{\text { M.E. }} \times 100\end{array}$ & $\begin{array}{c}\text { Per cent } \\
\mathrm{H}_{2} \mathrm{O}\end{array}$ & 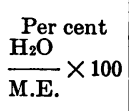 & $\begin{array}{l}\text { Per cent } \\
\mathrm{H}_{2} \mathrm{O}\end{array}$ & $\frac{\underset{\mathrm{H}_{2} \mathrm{O}}{\text { Per cent }}}{\text { M.E. }} \times 100$ \\
\hline $\begin{array}{l}\text { Untilled } \ldots \ldots \ldots \ldots \ldots \ldots \ldots \\
\text { Plowed } \ldots \ldots \ldots \ldots \ldots \ldots \ldots \\
\text { Harrowed } \ldots \ldots \ldots \ldots \ldots \ldots \\
\text { Smoothed } \ldots \ldots \ldots \ldots \ldots \ldots \\
\text { Disked and harrowed } \ldots \ldots \ldots \\
\text { Rolled and planted........ }\end{array}$ & $\begin{array}{l}19.3 \\
17.3 \\
16.4 \\
16.1 \\
16.1\end{array}$ & $\begin{array}{l}94.8 \\
84.8 \\
7 \\
80.5 \\
79.1 \\
79.1\end{array}$ & $\begin{array}{l}14.7 \\
12.8 \\
11.0 \\
11.2 \\
11.1\end{array}$ & $\begin{array}{l}78.2 \\
68.1 \\
\cdots \\
58.5 \\
59.7 \\
59.1\end{array}$ & $\begin{array}{l}23.5 \\
17.6 \\
20.0 \\
23.1 \\
16.2 \\
15.0\end{array}$ & $\begin{array}{l}89.4 \\
64.3 \\
75.2 \\
86.9 \\
61.0 \\
56.4\end{array}$ \\
\hline
\end{tabular}

the size distribution of aggregates and volume weights, and the relativesurface values, are given in figure 7.

Plowing had a very marked pulverizing effect on this soil (curves $A$ and $B$, fig. 7), but subsequent harrowing had no further effect, for the curves $(B$ and $C$ ) are almost coincident throughout their length, although the relative-surface value is slightly higher after harrowing. The plowing here caused a distinct decrease in the volume weight, but the harrowing had a slight compacting effect. The subsequent use of the float increased both the cloddiness and the volume weight; in fact, the volume weight was greater than before plowing, despite the fact that the field had previously been in pasture to sheep for a number of years. The increase in cloddiness brought about by the use of the float was caused by the wetness of the field when this operation was performed. Table 7 gives the moisture conditions of the three soil types on this farm at the time of sampling.

The Yolo clay loam had been given considerable time to dry out after the use of the float, so that when the field was disked and harrowed, it was at a very favorable moisture content for tillage operations. This operation (fig. 7, curve $E$ ) had a distinct pulverizing effect, and the field 
at this time was in its most finely pulverized condition. The planting and rolling operations increased the cloddiness only slightly. Disking and harrowing reduced the volume weight somewhat, but the subsequent planting and rolling altered it only slightly. This field, after final fitting and planting, was in a more pulverized condition than before treatment; the volume weight was only a little lower.

Seedbed for Alfalfa.-In 1934 a number of small plots were worked up for seeding alfalfa on the University Farm at Davis, California. After

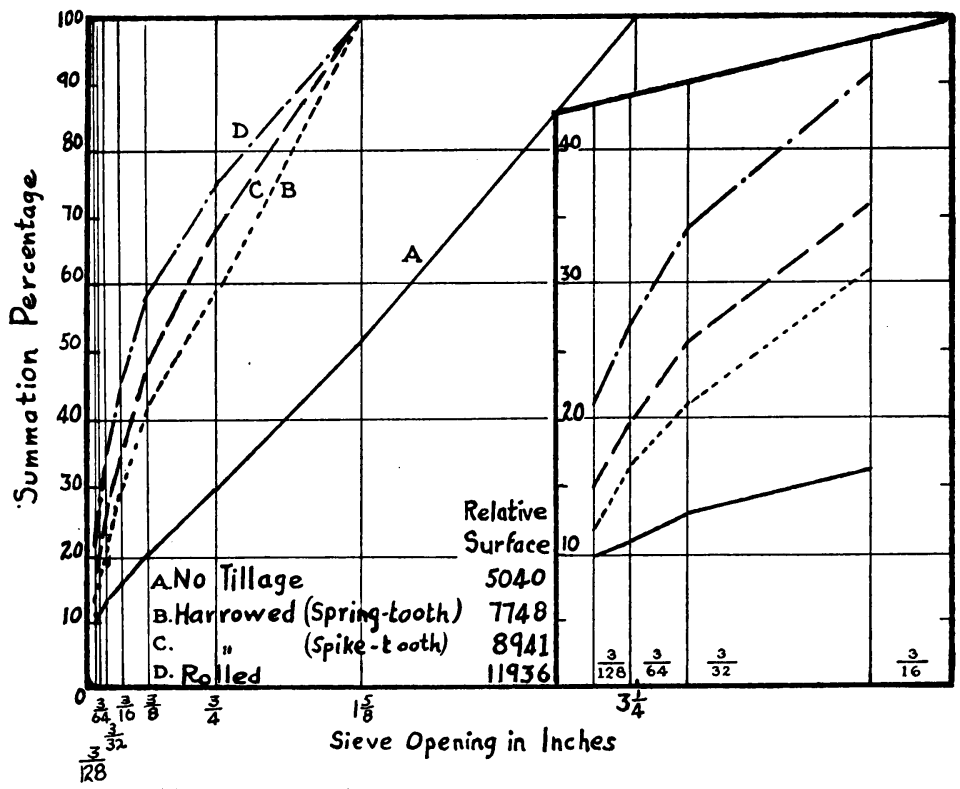

Fig. 8.- Size distribution of aggregates before and after tillage operations in preparation of seedbed for alfalfa on Yolo loam, plot D-15, 1934.

the seedbeds had all been prepared, but before they were seeded, there was a period of heavy rains. After the rains, the surface of the plots crusted over and had to be reworked. Samples were obtained from three of these plots, all on Yolo loam, as the tillage operations were being performed to reprepare the seedbeds. Since the plots here were very small, an 8-inch sampling cylinder was used instead of the 14-inch cylinder that had been used on the other samplings.

Three implements were used in working these plots for seeding. They were first worked with a spring-tooth harrow, then with a spike-tooth harrow, and finally with a spike-tooth roller. The data are plotted on figures 8,9 , and 10 . Two of the three plots behaved very much alike (figs. 8 and 9 ). In these two plots, each tillage operation had a distinct pulver- 


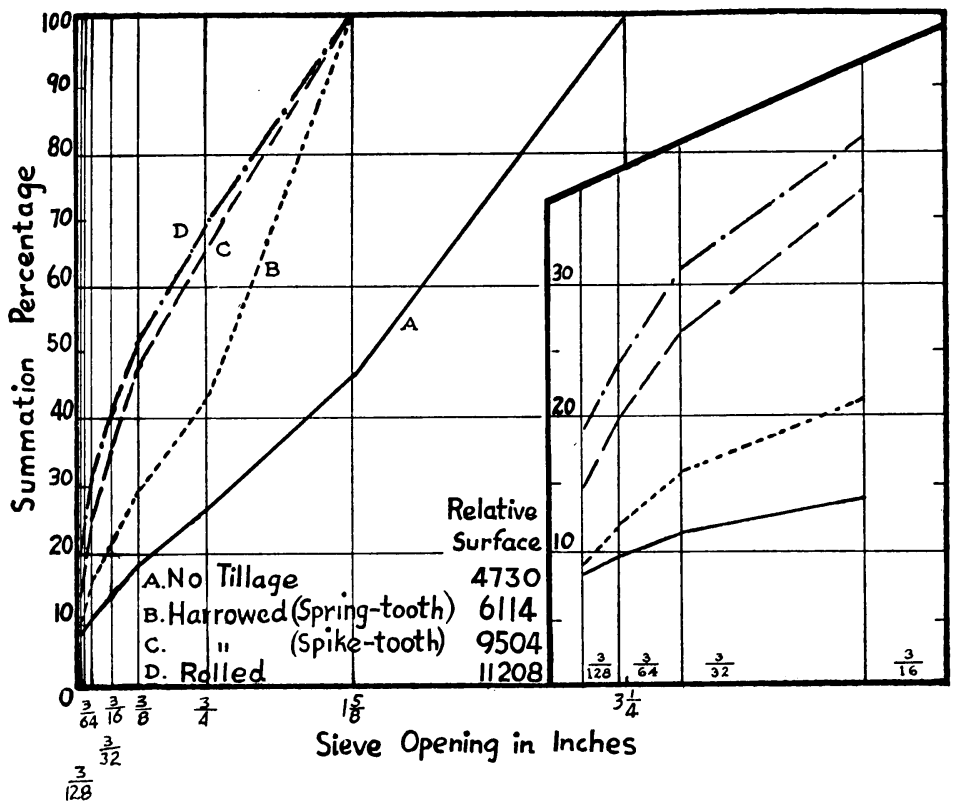

Fig. 9.-Size distribution of aggregates before and after tillage operations in preparation of seedbed for alfalfa on Yolo loam, plot D-25, 1934.

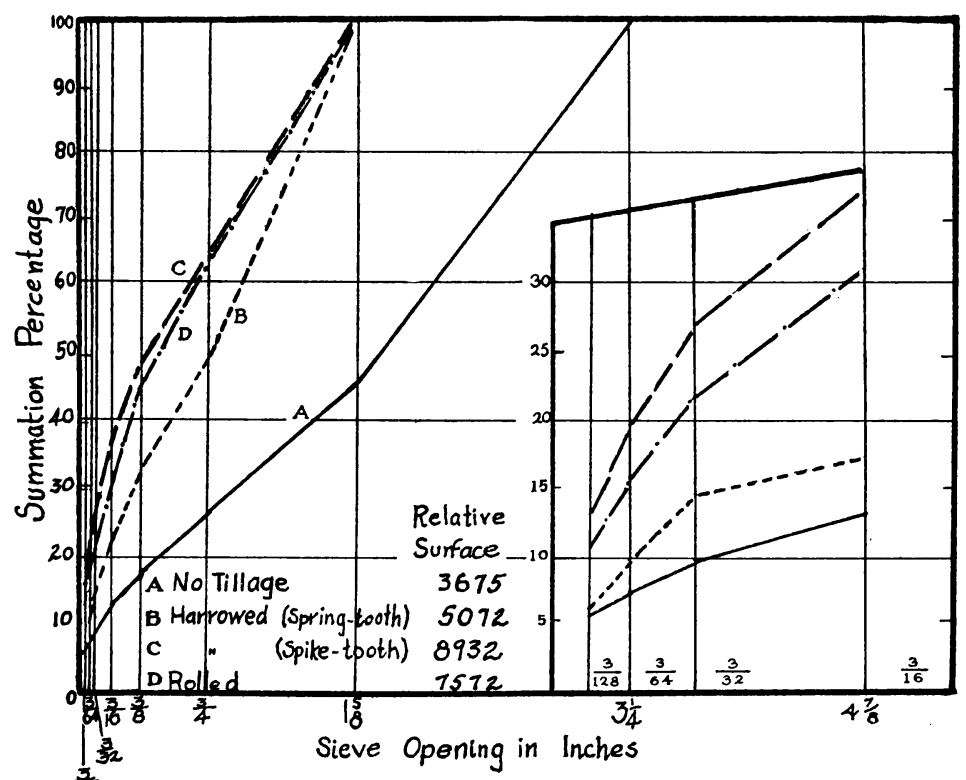

$\frac{3}{128}$

Fig. 10.-Size distribution of aggregates before and after tillage operations in preparation of seedbed for alfalfa on Yolo loam, plot D-35, 1934. 
izing effect, although the intensity of the effect was somewhat different: on plot D-15 (fig. 8) the spring-tooth harrow had a greater pulverizing effect than the spike-tooth harrow, whereas the pulverizing effect for these two implements was about the same on plot D-25 (fig. 9). Plot D-35 (fig. 10) is very similar to plot D-25 in the pulverizing effect of the dif-

TABLE 8

Dates of Treatments and Sampling on Yolo Loam Plots for Special Study

\begin{tabular}{|c|c|c|c|c|c|c|c|c|c|}
\hline & \multicolumn{3}{|c|}{1933} & \multicolumn{3}{|c|}{1934} & \multicolumn{3}{|c|}{1935} \\
\hline & Plot 1 & Plot 2 & Plot 3 & Plot 1 & Plot 2 & Plot 3 & Plot 1 & Plot 2 & Plot 3 \\
\hline Plowed.. & $\because$ & $3 / 4^{*}$ & $2 / 18^{*}$ & $\ldots$ & $6 / 7^{*}$ & $5 / 17^{*}$ & $\ldots$ & $\ldots$ & $\ldots$ \\
\hline Harrowed. & $\ldots$ & $4 / 3$ & $4 / 3$ & $\ldots$ & $6 / 15$ & $6 / 15$ & $\ldots$ & $\ldots$ & $\ldots$ \\
\hline Irrigated & $4 / 11$ & $4 / 11$ & $4 / 11$ & $5 / 1$ & $5 / 1$ & $5 / 1$ & & & \\
\hline \multirow[t]{5}{*}{ 1st series. . } & $4 / 14$ & $4 / 14$ & $4 / 14$ & $5 / 2$ & $5 / 2$ & $5 / 2$ & $4 / 30$ & $4 / 30$ & $4 / 30$ \\
\hline & $4 / 17$ & $4 / 17$ & $4 / 17$ & $5 / 3$ & $5 / 3$ & $5 / 3$ & $\ldots$ & $\ldots$ & $\ldots$ \\
\hline & $4 / 20$ & $4 / 20$ & $4 / 20$ & $5 / 4$ & $5 / 4$ & $5 / 4$ & $\ldots$ & $\cdots$ & $\ldots$ \\
\hline & $5 / 11$ & $5 / 11$ & $5 / 11$ & $7 / 3$ & $7 / 3$ & $7 / 3$ & $\ldots$ & $\ldots$ & $\ldots$ \\
\hline & $5 / 12$ & $5 / 12$ & $5 / 12$ & $7 / 5$ & $7 / 5$ & $7 / 5$ & $\ldots$ & $\ldots$ & $\ldots$ \\
\hline \multirow[t]{4}{*}{ 2nd series. } & $5 / 13$ & $5 / 13$ & $5 / 13$ & $7 / 6$ & $7 / 6$ & $7 / 6$ & $\ldots$ & $\ldots$ & $\ldots$ \\
\hline & $5 / 15$ & $5 / 15$ & $5 / 15$ & $\ldots$ & $\ldots$ & $\ldots$ & $\ldots$ & $\ldots$ & $\ldots$ \\
\hline & $5 / 16$ & $5 / 16$ & $5 / 16$ & $\ldots$ & $\ldots$ & $\ldots$ & $\ldots$ & $\ldots$ & $\ldots$ \\
\hline & $7 / 24$ & $7 / 24$ & $7 / 24$ & $\ldots$ & $\ldots$ & $\ldots$ & $\ldots$ & $\ldots$ & $\ldots$ \\
\hline \multirow[t]{2}{*}{ 3rd series. } & $7 / 25$ & $7 / 25$ & $7 / 25$ & $\ldots$ & $\ldots$ & $\ldots$ & $\ldots$ & $\ldots$ & $\ldots$ \\
\hline & $7 / 26$ & $7 / 26$ & $7 / 26$ & $\ldots$ & $\ldots$ & $\ldots$ & $\ldots$ & $\ldots$ & $\ldots$ \\
\hline \multirow[t]{2}{*}{ 4th series. } & $12 / 1$ & $12 / 1$ & $12 / 1$ & $\cdots$ & $\cdots$ & $\cdots$ & $\ldots$ & $\cdots$ & $\ldots$ \\
\hline & $3 / 4$ & $3 / 4$ & $3 / 4$ & $5 / 19$ & $5 / 18$ & $5 / 14$ & $4 / 30$ & $4 / 30$ & $4 / 30$ \\
\hline \multirow[t]{3}{*}{ Sampled. } & $5 / 4$ & $4 / 3$ & $4 / 3$ & $7 / 25$ & $6 / 11$ & $6 / 11$ & $6 / 3$ & $6 / 3$ & $6 / 3$ \\
\hline & $12 / 1$ & $5 / 4$ & $5 / 4$ & $\cdots$ & $6 / 15$ & $6 / 15$ & $\ldots$ & $\ldots$ & $\ldots$ \\
\hline & & $12 / 1$ & $12 / 1$ & $\ldots$ & $7 / 26$ & $7 / 26$ & $\ldots$ & $\ldots$ & \\
\hline
\end{tabular}

* Moisture content when plowed: 1933, plot 2, 20.0 per cent; plot 3, 25.4 per cent; 1934, plot 2, 16.1 per cent; plot $3,23.2$ per cent.

ferent harrows. The rolling had a distinct pulverizing effect on plots D-15 and D-25, but the cloddiness on plot D-35 was increased somewhat by this operation. This plot was in a slight depression and had a higher moisture content when worked, which undoubtedly accounts for the increased cloddiness caused by rolling.

The relative-surface values are given with the legend on each figure. In some instances two curves may appear very close together, yet there will be fairly wide differences in their relative-surface values-compare, for example, curves and relative-surface values for spike-tooth harrowing and for rolling, in figures 9 and 10 . In each case, the sample with the higher relative-surface value has the greater percentage of the finer frac- 
tions. This is shown in the enlargements of this portion of the curve in the lower right-hand corner of each figure.

Tillage Operations at Different Moisture Contents.-A number of samplings were taken for size distribution of aggregate studies after plowing, harrowing, and irrigation treatments on two sets of plots on the

TABLE 9

Dates of Treatments and Sampling on Yolo Silt Loam Plots for Special Study

\begin{tabular}{|c|c|c|c|c|c|c|c|c|c|}
\hline & \multicolumn{3}{|c|}{1933} & \multicolumn{3}{|c|}{1934} & \multicolumn{3}{|c|}{1935} \\
\hline & Plot 1 & Plot 2 & Plot 3 & Plot 1 & Plot 2 & Plot 3 & Plot 1 & Plot 2 & Plot 3 \\
\hline Plowed. & $\ldots$ & $3 / 4^{*}$ & $2 / 18^{*}$ & $\ldots$ & $6 / 7^{*}$ & $5 / 17^{*}$ & $\ldots$ & $\ldots$ & $\ldots$ \\
\hline Harrowed. & $\ldots$ & $4 / 3$ & $4 / 3$ & $\ldots$ & $6 / 15$ & $6 / 15$ & $\ldots$ & $\ldots$ & $\ldots$ \\
\hline Irrigated & $4 / 4$ & $4 / 4$ & $4 / 4$ & $5 / 1$ & $5 / 1$ & $5 / 1$ & $5 / 1$ & $5 / 12$ & $5 / 1$ \\
\hline \multirow{4}{*}{ 1st series. } & $4 / 5$ & $4 / 5$ & $4 / 5$ & $5 / 2$ & $5 / 2$ & $5 / 2$ & $\ldots$ & $\ldots$ & $\ldots$ \\
\hline & $4 / 10$ & $4 / 10$ & $4 / 10$ & $5 / 3$ & $5 / 3$ & $5 / 3$ & $\ldots$ & $\ldots$ & $\ldots$ \\
\hline & $\ldots$ & $\ldots$ & $\ldots$ & $5 / 4$ & $5 / 4$ & $5 / 4$ & $\ldots$ & $\ldots$ & $\ldots$ \\
\hline & $5 / 12$ & $5 / 12$ & $5 / 12$ & $7 / 3$ & $7 / 3$ & $7 / 3$ & . & $\ldots$ & $\ldots$ \\
\hline \multirow[t]{3}{*}{ 2nd series. } & $5 / 15$ & $5 / 15$ & $5 / 15$ & $7 / 5$ & $7 / 5$ & $7 / 5$ & $\cdots$ & $\cdots$ & $\cdots$ \\
\hline & $5 / 16$ & $5 / 16$ & $5 / 16$ & $7 / 6$ & $7 / 6$ & $7 / 6$ & $\ldots$ & $\ldots$ & $\ldots$ \\
\hline & $7 / 26$ & $7 / 26$ & $7 / 26$ & $\ldots$ & $\ldots$ & $\ldots$ & $\ldots$ & $\ldots$ & $\ldots$ \\
\hline \multirow[t]{3}{*}{ 3rd series. } & $7 / 27$ & $7 / 27$ & $7 / 27$ & $\cdots$ & $\cdots$ & $\cdots$ & $\cdots$ & $\cdots$ & $\cdots$ \\
\hline & $7 / 28$ & $7 / 28$ & $7 / 28$ & $\ldots$ & $\ldots$ & $\ldots$ & $\ldots$ & $\ldots$ & $\ldots$ \\
\hline & $3 / 25$ & $3 / 25$ & $3 / 25$ & $5 / 19$ & $5 / 22$ & $5 / 15$ & $5 / 1$ & $5 / 1$ & $5 / 1$ \\
\hline \multirow{3}{*}{ Sampled. } & $\ldots$ & $4 / 3$ & $4 / 3$ & $7 / 26$ & $6 / 11$ & $6 / 11$ & $6 / 3$ & $6 / 3$ & $6 / 3$ \\
\hline & $5 / 4$ & $5 / 4$ & $5 / 4$ & $\ldots$ & $6 / 15$ & $6 / 15$ & $\ldots$ & $\ldots$ & $\ldots$ \\
\hline & $12 / 2$ & $12 / 2$ & $12 / 2$ & $\ldots$ & $7 / 26$ & $7 / 26$ & $\ldots$ & $\ldots$ & $\ldots$ \\
\hline
\end{tabular}

* Moisture content when plowed: 1933, plot 2, 20.0 per cent; plot 3, 24.5 per cent; 1934, plot 2, 17.6 per cent; plot 3, 23.2 per cent.

University Farm that were laid out for water-penetration studies as affected by tillage at different moisture contents. The moisture-penetration studies were made in coöperation with N. E. Edlefsen of the Division of Irrigation Investigations and Practice; the results of these will not be reported here. The two sets of plots were located on Yolo loam and Yolo silt loam, and there were three plots in each set. One plot received no tillage, one was plowed at what was considered a favorable moisture content for plowing, and the other was plowed at moisture contents that were considered too high to obtain the most favorable results from tillage (see footnote, tables 8 and 9). Both of the plowed plots were harrowed lightly after they had been plowed. The plots were $45 \times 90$ feet and were plowed with a two-horse plow in one direction only, so as not to produce a back furrow in the center of each plot.

After the tillage operations had been completed on both plots in each 
set, all three plots were seeded to barley, primarily to keep out weeds. One to four series of irrigations were made on each plot (tables 8 and 9), and the rate of penetration of water into the soil was determined. After each tillage operation, the two tilled plots in each set were sampled; and after some of the series of irrigations, all of the plots in each set were sampled. Samples were taken to 7 -inch depths and in 4 replicates. Each sampling removes considerable soil, so that sampling for size distribution of aggregates could not be done after each series of irrigations for fear of altering the rate of water penetration. Tables 8 and 9 give dates of treatments and sampling on these two sets of plots. During the 1934 season, because of conditions which could not be controlled, the plowing was not done until fairly late on these plots, so that before any cultural treatments were made, all plots were subjected to a series of irrigations.

The results of the samplings on these areas are given in the form of graphs similar to those previously presented. For convenience in discussing the graphs, the plots of each set are numbered as follows : plot 1 received no tillage, plot 2 was plowed at favorable moisture content, and plot 3 was plowed while too wet. Figures 11 and 12 give the results on plots 2 and 3 for the 1933 season and figures 13 and 14 for the same plots for the 1934 season. ${ }^{6}$

The plowing (fig. 11) had a definite pulverizing effect on plot 2 , which was plowed at a favorable moisture content ; but plot 3 , which was plowed too wet, was more cloddy after plowing than it had been originally. The plowing in the latter case was done when the soil was too wet to scour off the plowshare. The soil seemed to push up in front of the plow and was thus compacted, which increased the cloddiness. Harrowing had no pulverizing effect on the area plowed at suitable moisture content, in fact, the curve showing the result of this treatment falls slightly below that for plowing (fig. 11, curves $B$ and $C$ ). This slight difference is probably due to the natural heterogeneity of the soil rather than to any effect of tillage. On the plot that was plowed too wet, some pulverizing of the soil, mostly increasing the finer fraction, was caused by harrowing. The amount of coarse material is about the same, but the increase in the fine material accounts for the increase in the relative-surface value (fig. 11, curves $D$ and $E$ ).

For the same season, on Yolo silt loam (fig. 12), the plowing had a definite pulverizing effect on both areas, but the action was more pro-

\footnotetext{
${ }^{6}$ In order to reduce the number of samplings on plots 2 and 3, they were not sampled before plowing, but the sampling on plot 1 taken at that time is used for these plots. Since the areas are fairly uniform and the plots are small, these results are probably very close to what would have been obtained for the other plots had they been sampled at this time.
} 


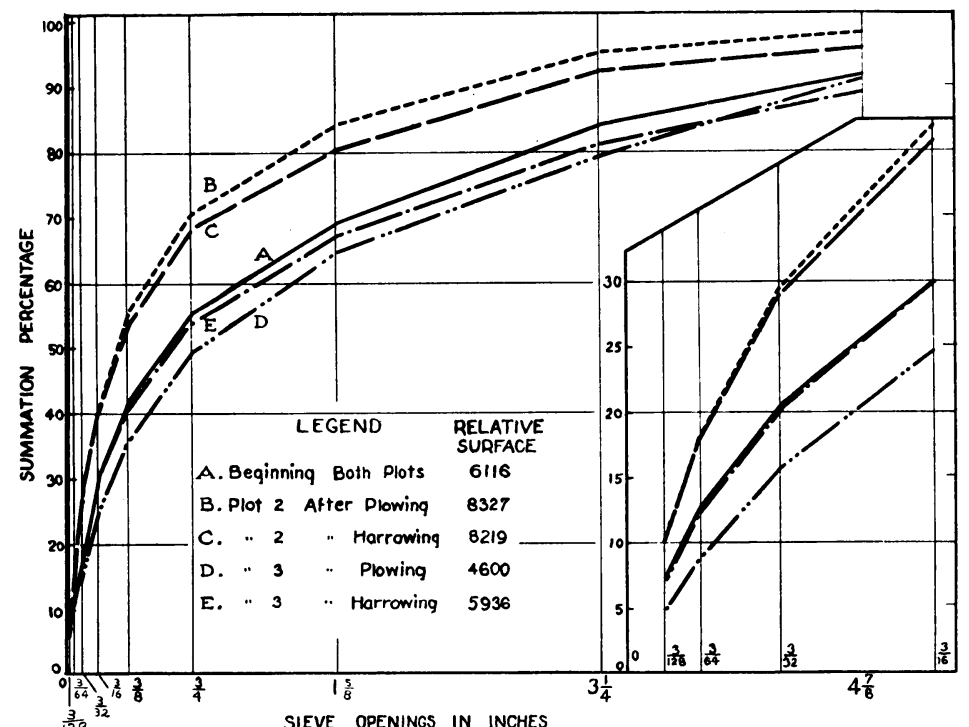

Fig. 11.- Size distribution of aggregates before and after tillage operations on plots 2 and 3 on Yolo loam, 1933.

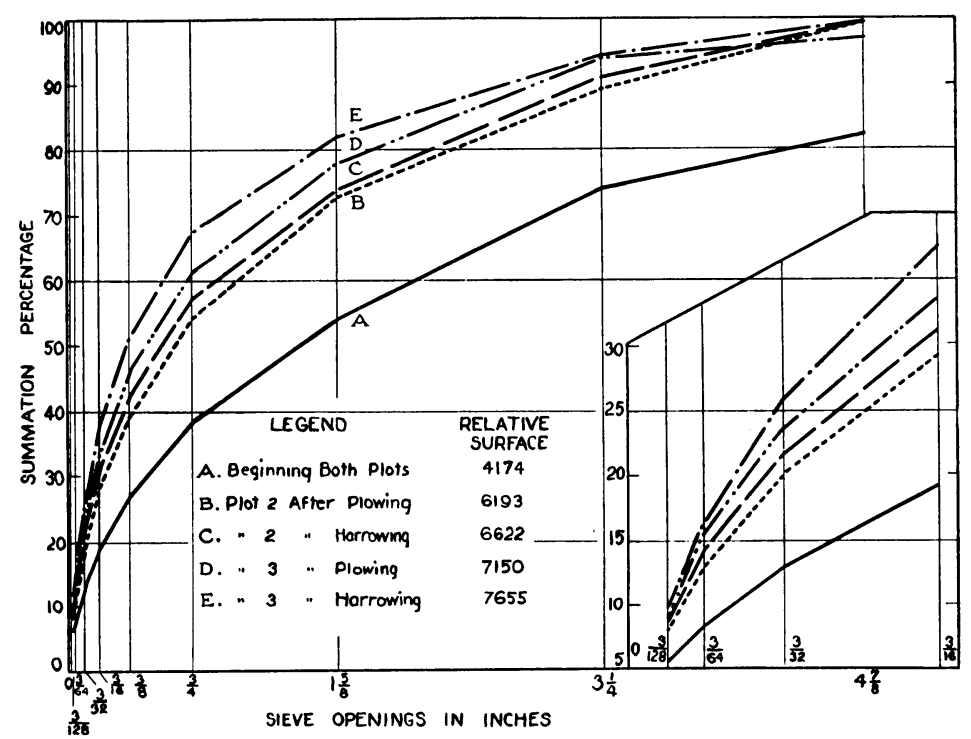

Fig. 12.-Size distribution of aggregates before and after tillage operations on plots 2 and 3 on Yolo silt loam, 1933. 
nounced on the plot (No. 3) plowed at the higher moisture content. In this instance, however, although the furrow slice coming off the plowshare had a very slick shiny surface, the soil was not wet enough to prevent the soil from scouring off the plowshare.

Harrowing on these two plots seems to have had only a slight pulverizing effect. In both cases the curve for the harrowing treatment is slightly above that for plowing. There is some increase in the relative-surface values and, as shown on the enlargement of the lower end of the curves, some increase in the finer fractions.

In 1934 on Yolo loam (fig. 13), the plot that had been plowed too wet the year before was more cloddy before plowing than the one that had been plowed at a favorable moisture content. Plowing had a very definite pulverizing effect on both plots. The pulverizing effect on the wet plot was slightly greater than that on the drier one. The curves ( $B$ and $E$ ) for the plots after plowing fall closer together than those $(A$ and $D)$ for the plots before plowing. The numerical increases in the relative-surface values are similar for the two plots : the increase on the drier plot was from 4,718 to 7,186, an increase of 2,468; and on the wet plot from 2,936 to 5,463 , an increase of 2,527 .

Harrowing had a pulverizing effect on both areas (curves $C$ and $F$ ). Here again, the amount of pulverizing on the wet plot exceeds that on the drier plot for this treatment. After both tillage operations, plot 2, the drier plot, was still in a slightly finer state of pulverization than plot 3 .

For the same season, on Yolo silt loam (fig. 14), the curves ( $A$ and $D$ ) for the size distribution of aggregates before treatment fall very close together, yet there is considerable difference in the relative-surface values. Here again the large difference in this value is caused by the difference in the finest fraction. The curves are almost parallel, but curve $A$ starts slightly above curve $D$.

Plowing had a distinct pulverizing effect on both plots, with a slightly greater effect on the drier plot, while harrowing had no pulverizing effect on the drier plot and only a very slight effect on the wet plot. After both tillage operations, the curve $(C)$ for plot 2 is slightly higher than that $(F)$ for plot 3 , but the curves lie very close to each other throughout their length. The tillage operations seem to have had a very similar effect on both plots for this soil type.

In order to compare the results of treatments on the different soil types, the data were replotted. Figure 15 shows for the two soil types the results of tillage operations on the plots plowed at favorable moisture conditions in 1933.

The curves in figure 15 indicate that, when plowing was done at a 


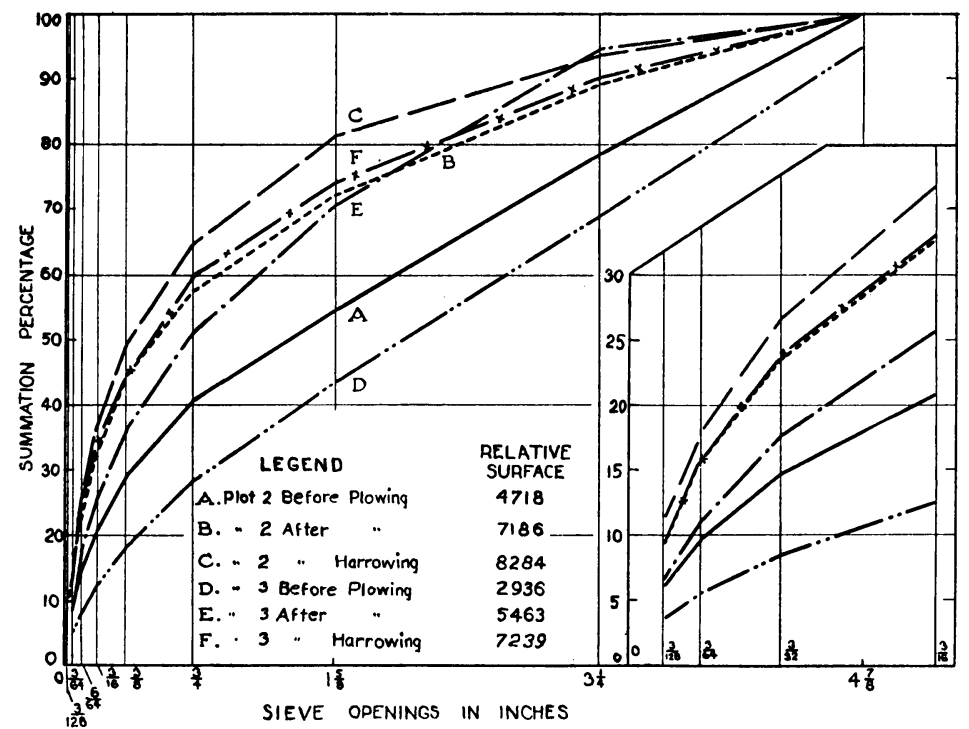

Fig. 13.- Size distribution of aggregates before and after tillage operations on plots 2 and 3 on Yolo loam, 1934.

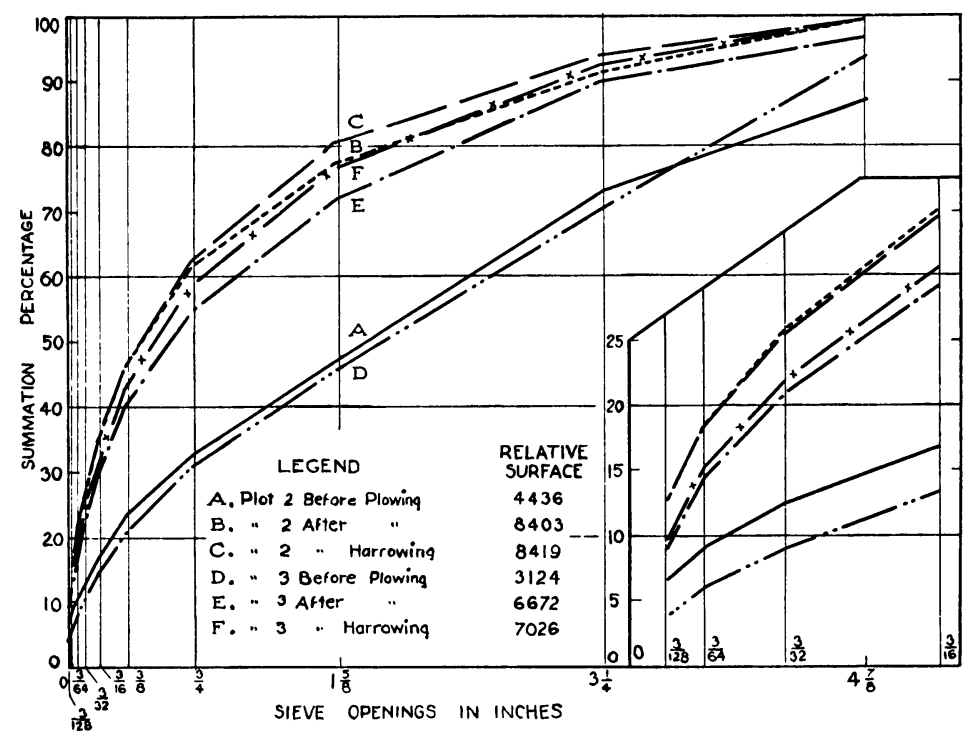

Fig. 14. - Size distribution of aggregates before and after tillage operations on plots 2 and 3 on Yolo silt loam, 1934. 
favorable moisture content, the effects of tillage operations were very similar on the two soil types. The Yolo silt loam was more cloddy before any tillage and also more cloddy after the tillage. On both types, the curves for the plowing and harrowing are very close together, although on the Yolo silt loam the relative-surface value after plowing is slightly

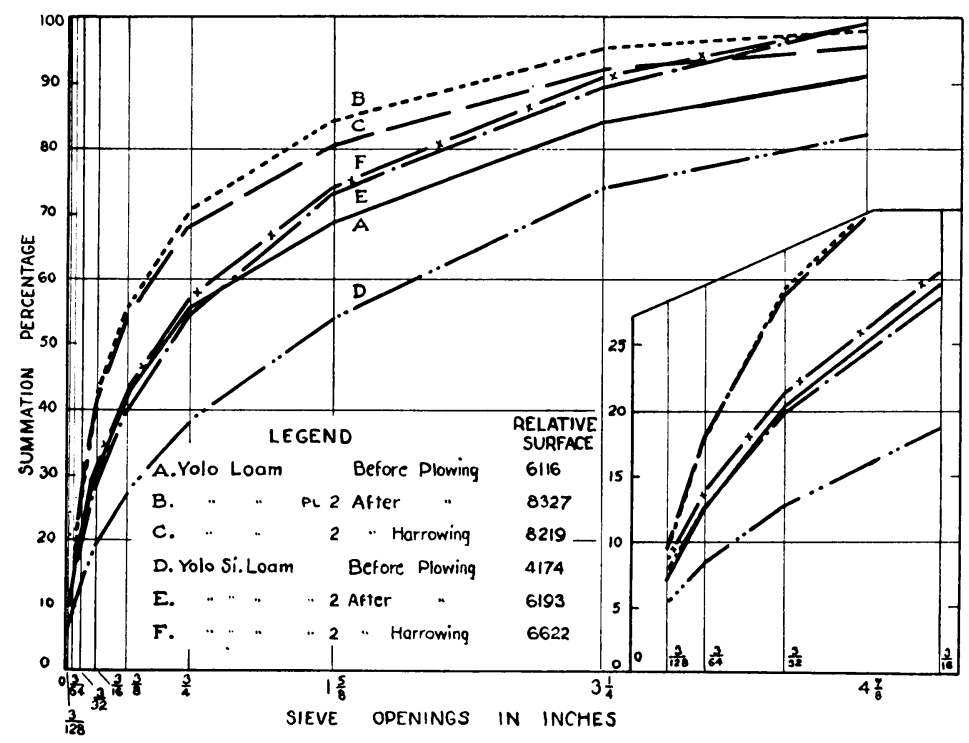

Fig. 15.-Size distribution of aggregates before and after tillage operations on plot 2 of both Yolo loam and Yolo silt loam, 1933. (Curves $A$ and $D$ from plot 1 ).

lower than after harrowing; on the Yolo loam, the relative-surface values for the two treatments are almost identical.

Similar graphs were made for plot 2 for 1934 and for plot 3 for each year, but since this constitutes merely a regrouping of the curves already given in figures $11,12,13$, and 14 , these graphs are omitted.

A comparison of curves $A, B$, and $C$ on figures 13 and 14, shows that on plot 2 for 1934 on both soils, there was a stronger pulverizing effect on the silt loam, although both plots showed a very definite decrease in cloddiness. Harrowing in this year had a distinct pulverizing effect on the loam but no effect on the silt loam. After the tillage operations, these two soils were in very much the same condition (curve $C$, figs. 13 and 14).

With the plots plowed at high moisture contents, there was in 1933 a strong contrast in the effect of plowing. Before plowing, the Yolo loam was less cloddy than the silt loam (curve $A$, figs. 11 and 12), but the plowing increased the cloddiness on the loam plot and decreased it on the silt loam (curve $D$, figs. 11 and 12 ), so that after plowing the condi- 
tion of the two plots was just reversed. Harrowing had a definite pulverizing effect on the loam and only a slight pulverizing effect on the silt loam. At the end of the tillage operations the former was nearly the same as it was originally, whereas the latter was much less cloddy.

Next year both plots that had been plowed too wet were in about the same condition before plowing, but materially more cloddy than they were the previous year. The plowing greatly reduced the cloddiness on both plots (curves $D$ and $E$, figs. 13 and 14) but especially on the silt loam. The harrowing had only a slight effect on both plots (curve $F$, figs. 13 and 14) but was slightly more effective in pulverizing the loam plot, so that after the tillage operations, both plots were again very similar but much less cloddy than they had been before the tillage operations.

\section{EFFECT OF IRRIGATION ON SIZE DISTRIBUTION OF AGGREGATES}

The same two areas were sampled after some of the series of irrigations, and the size distribution of the aggregates after the irrigation may be compared with that before irrigation. The irrigation water was applied in basins to depths of about 6 inches at each application. On these plots there were from 3 to 5 applications of water, usually only a day or two apart. Figures 16 and 17 give the curves for the size distribution of aggregates for the Yolo loam and Yolo silt loam plots for 1933. In all cases there was some increase in cloddiness after the irrigation.

On the Yolo loam (fig. 16), a great increase in cloddiness occurred on the untilled check plot (No. 1) and on plot 2, which was plowed at a favorable moisture content. On plot 3 , plowed too wet, there was only a slight change in the relative-surface value, yet the curves $(E$ and $F)$ are rather well separated in the upper half. They are, however, very close for the three finest fractions, which have the greatest influence on the relative-surface value. The peculiar behavior of this plot is further reflected in the slightness of its change after the irrigation treatment as compared to the other two plots sampled at the same period.

On the untilled Yolo silt loam, according to the curves (fig. 17, curves $A$ and $B$ ), a considerable increase in the cloddiness was caused by irrigation. But this difference is not reflected in the relative-surface values for these two treatments : there is a slight difference, showing possibly a slight increase in cloddiness, but not nearly so much as one would expect from the comparison of the two curves. The slightly greater amount of the two finest fractions after the irrigation treatment accounts for this. Irrigation of the two plots that had been tilled caused an increase in the cloddiness. The increase was far greater, however, in the plot plowed too 


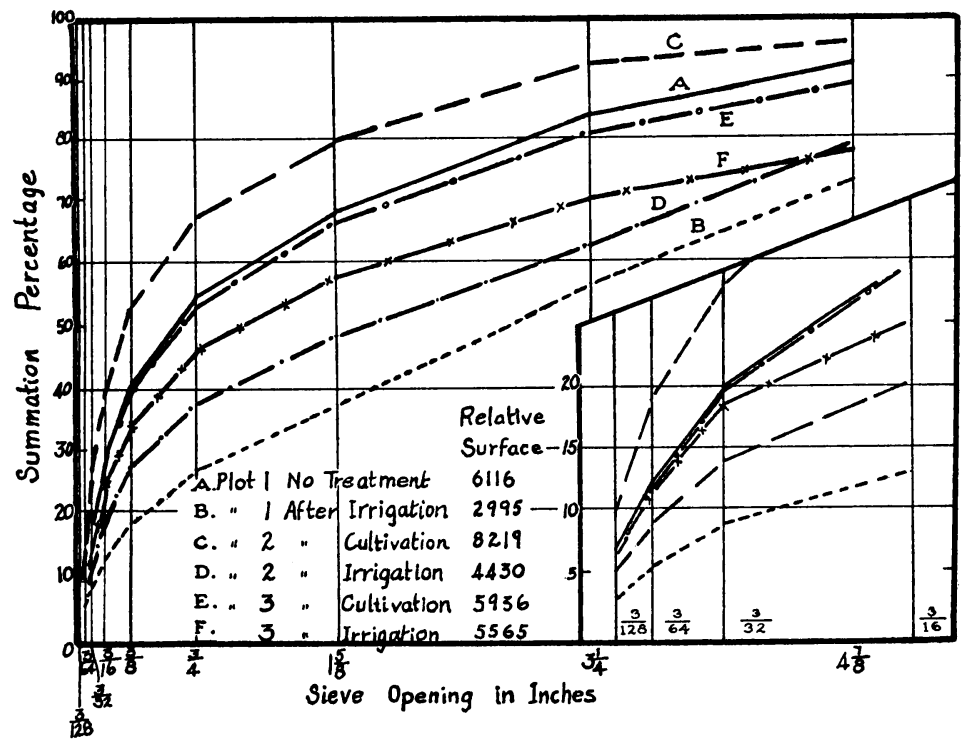

Fig. 16.-Size distribution of aggregates before and after irrigation on all three plots on Yolo loam, 1933.

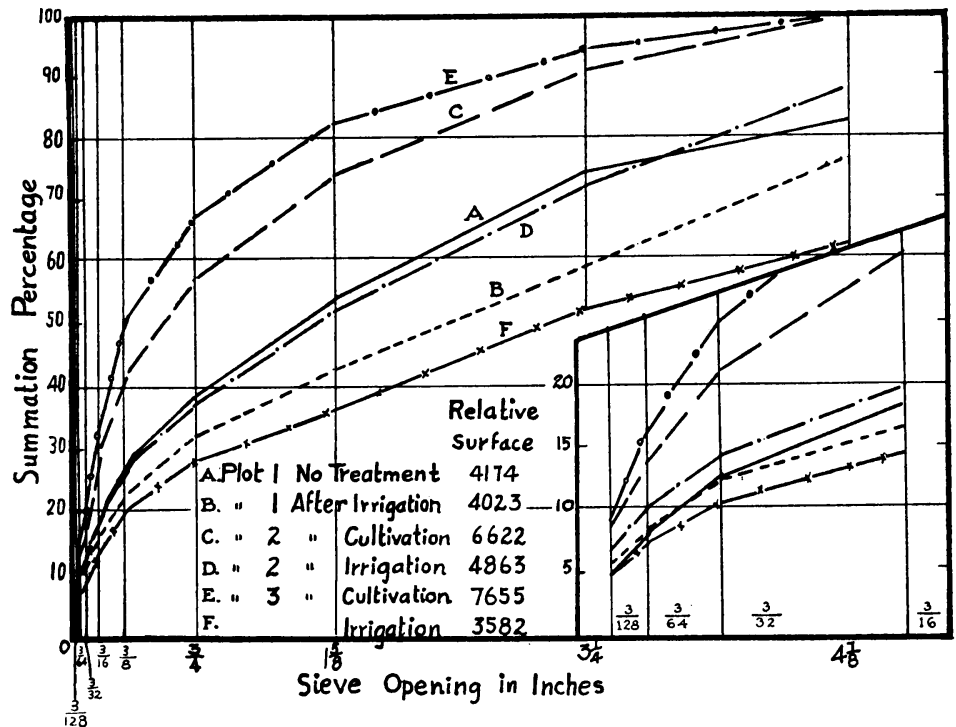

Fig. 17.-Size distribution of aggregates before and after irrigation on all three plots on Yolo silt loam, 1933. 
wet (curves $E$ and $F$ ) than in the one plowed under favorable moisture conditions (curves $C$ and $D$ ). On these two plots, the differences in both the curves and the relative-surface value are pronounced.

Figures 18 and 19 show the results of similar treatments on the same two soil types for 1934. On the Yolo loam during this season there was a definite increase in cloddiness after the irrigation treatments on each of the plots. The change was not so pronounced for this year as it had been the previous year for the plot receiving no tillage operations. The plot plowed too wet showed a greater increase in cloddiness this season than it had the season before, whereas the plot plowed under favorable moisture conditions behaved about the same during the two seasons.

On the Yolo silt loam (fig. 19), the untilled plot showed no difference in its condition before and after the irrigation treatment and, in fact, not much difference from its condition at the beginning of these investigations in 1933. The relative-surface values before any treatments and after the irrigation treatments in $\mathbf{1 9 3 4}$ are very close. There was a great increase in the cloddiness after irrigation on the other two plots on this same soil. On the plot plowed under favorable moisture conditions, the increase for this season was far greater than was the case for the previous season, whereas the behavior of the plot plowed too wet was very similar for both seasons.

After the tillage operations on each series of plots in 1933, the plots were all irrigated, then planted to barley. During the summer, two more series of irrigations were made, the last one near the end of July. The plots were permitted to remain untouched thereafter until early in December, when they were again sampled. The results are given in figures 20 and 21. There does not appear to be any consistent order of change. Some of the plots are more cloddy and some are less cloddy than at the previous sampling period.

The results on the Yolo loam (fig. 20) show a much less cloddy condition for plot 1 at the later sampling period. Curves $A$ and $B$ are wide apart and the relative-surface values are 2,995 and 5,728, respectively. The plot plowed at a favorable moisture content was only slightly altered (curves $C$ and $D$ ), whereas the plot plowed at a very high moisture content was somewhat cloddier at the end of the season.

The variability between plots is not nearly so great on the Yolo silt loam (fig. 21). On this soil there was little or no difference in the aggregate condition of plot 1 at the beginning and end of the season according to the curves ( $A$ and $B$ ), and only a very slight difference according to the relative-surface values. Plot 2 was somewhat more cloddy at the later sampling period and plot 3 much less so. 


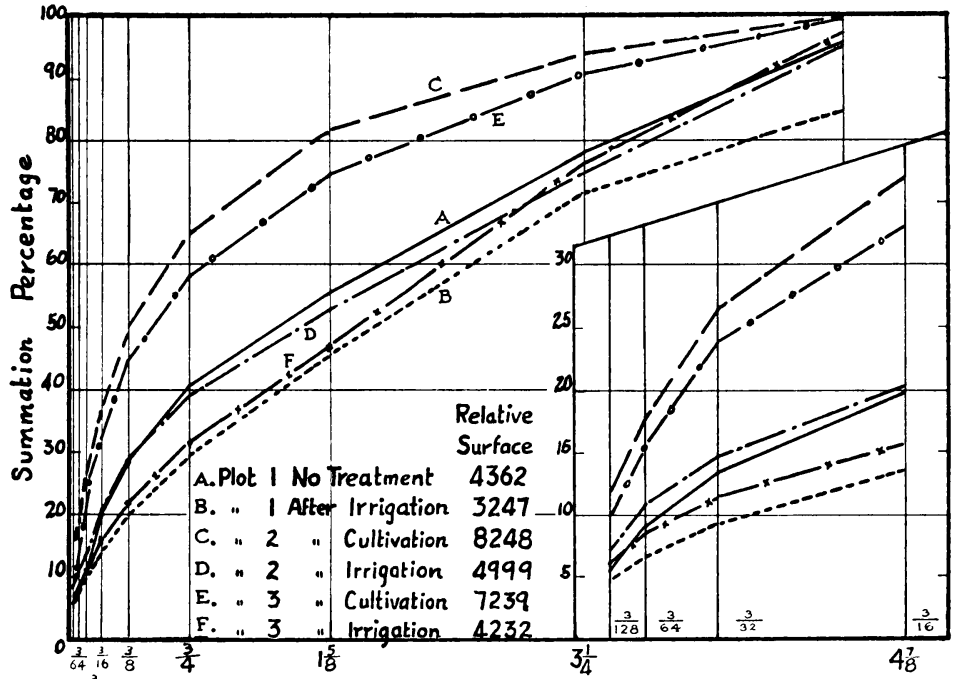
$\frac{3}{128}^{\frac{3}{32}}$

Sieve Opening in Inches

Fig. 18.- Size distribution of aggregates before and after irrigation on all three plots on Yolo loam, 1934.

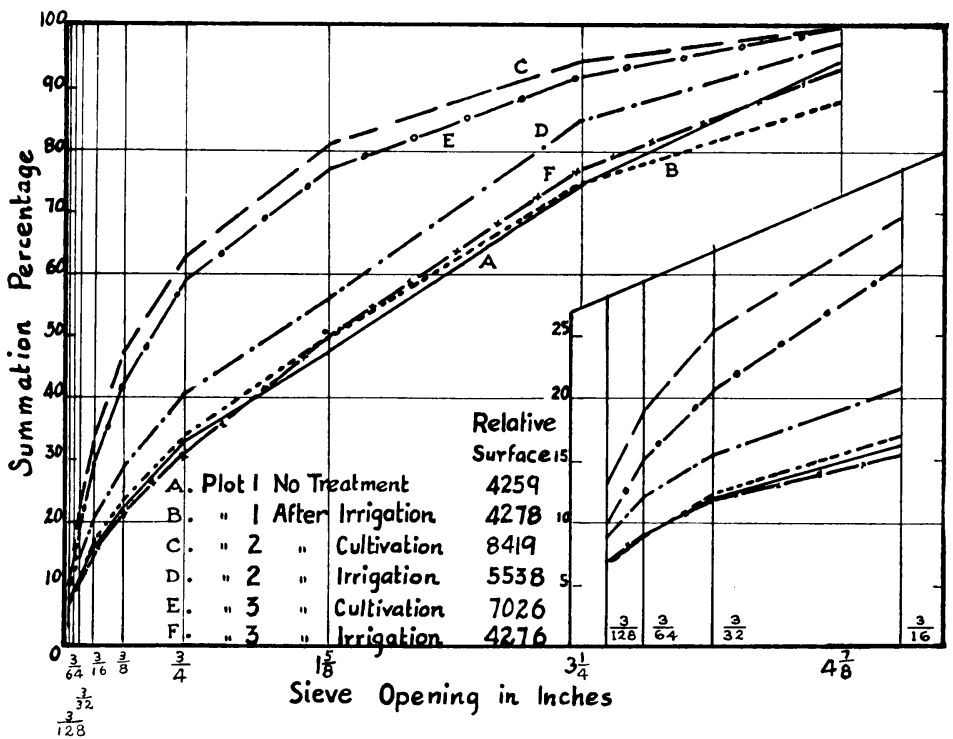

Fig. 19.-Size distribution of aggregates before and after irrigation on all three plots on Yolo silt loam, 1934. 


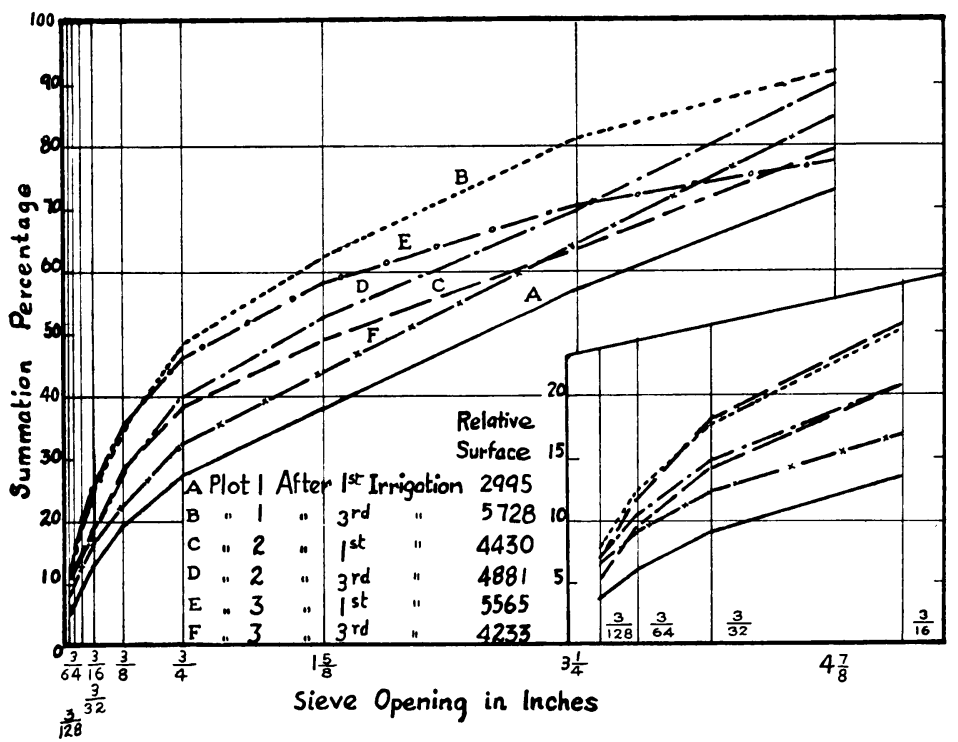

Fig. 20.- Size distribution of aggregates after the first and third irrigations on all three plots on Yolo loam, 1933.

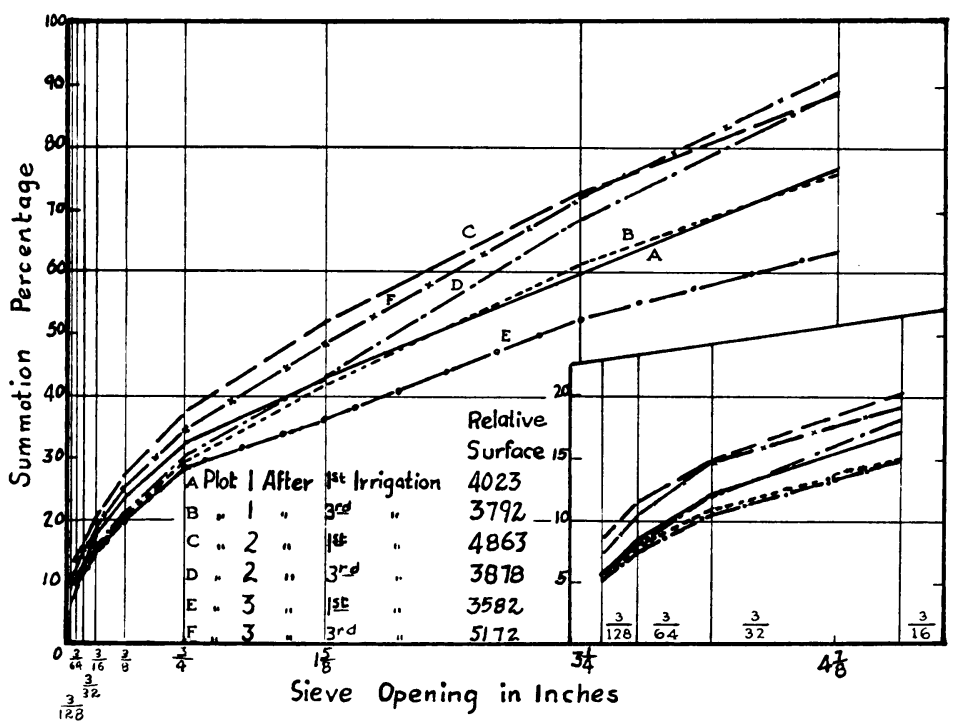

Fig. 21.- Size distribution of aggregates after the first and third irrigations on all three plots on Yolo silt loam, 1933. 
The results on the two soils are directly contrasting: where there was a strong decrease in the cloddiness in plot 1 of the Yolo loam, there was practically no change for the same plot on the Yolo silt loam. On plot 2 of the Yolo loam there was a slight decrease in cloddiness and a rather definite increase on the Yolo silt loam. On plot 3 there was a definite increase in cloddiness on the Yolo loam and a slightly greater decrease on the Yolo silt loam. There does not seem to be any satisfactory explanation for the consistent contrast between these two soils in their responses to repeated irrigations. The results of the tillage operations already given were fairly consistent for both of these soils.

The effect of irrigation after tillage on the Yolo clay loam and Capay adobe clay, where the fields were being prepared for seedbed, has already been mentioned (figs. 3 and 4, p. 445). In both of these instances, as was the case with nearly all others, irrigation following cultivation caused an increase in cloddiness of the soil, so that the field, after irrigation, was more cloddy than before it was tilled.

\section{SEASONAL VARIATIONS}

The variation of the size distribution of aggregates from season to season is often as great as changes brought about by tillage operations or application of irrigation water. The seasonal changes were observed on the series of plots on Yolo loam and Yolo silt loam described in the preceding section.

In the spring of 1934 all plots were irrigated before the samples were taken, so that the changes occurring in the size distribution of aggregates over the winter period were not determined. The results for the period between the last sampling in 1934 and the first sampling in 1935 are given in figures 22,23 , and 24 . In all plots on both soil types, the soils are more cloddy in the spring than they were the previous fall. The changes are greater on the Yolo silt loam than on the Yolo loam. On plots 1 and 2 (figs. 22 and 23) at the last sampling in 1934, the Yolo loam was somewhat coarser than the Yolo silt loam, and on plot 3 (fig. 24), the two soils had about the same size distribution of aggregates. When samplings were taken the following spring, plot 1 on the Yolo loam, according to its relative-surface value, was slightly coarser than the same plot on the Yolo silt loam, although, except for a short distance at the finer end, the curve $(B)$ of size distribution for Yolo loam lies above that $(D)$ for Yolo silt loam. On the other two plots, the Yolo silt loam is slightly coarser than the Yolo loam.

There is a great increase in the cloddiness of all plots at the conclusion of the sampling period in the spring of 1935 over that at the beginning 


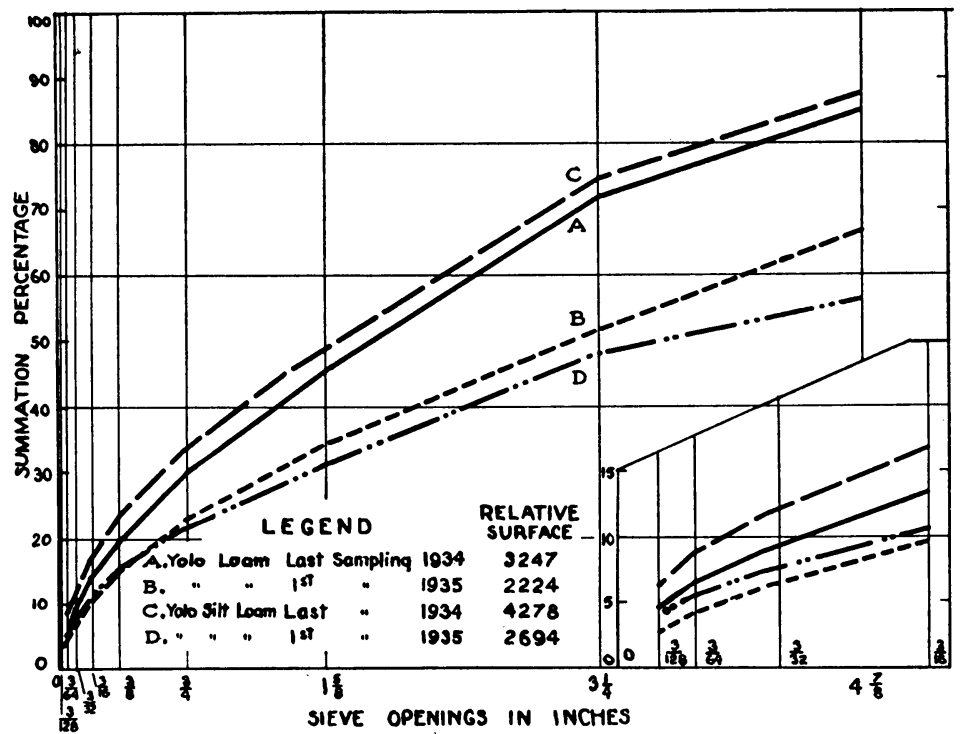

Fig. 22.-Changes in size distribution of aggregates on plot 1 of Yolo-loam and Yolo-silt-loam areas during the winter 1934-35.

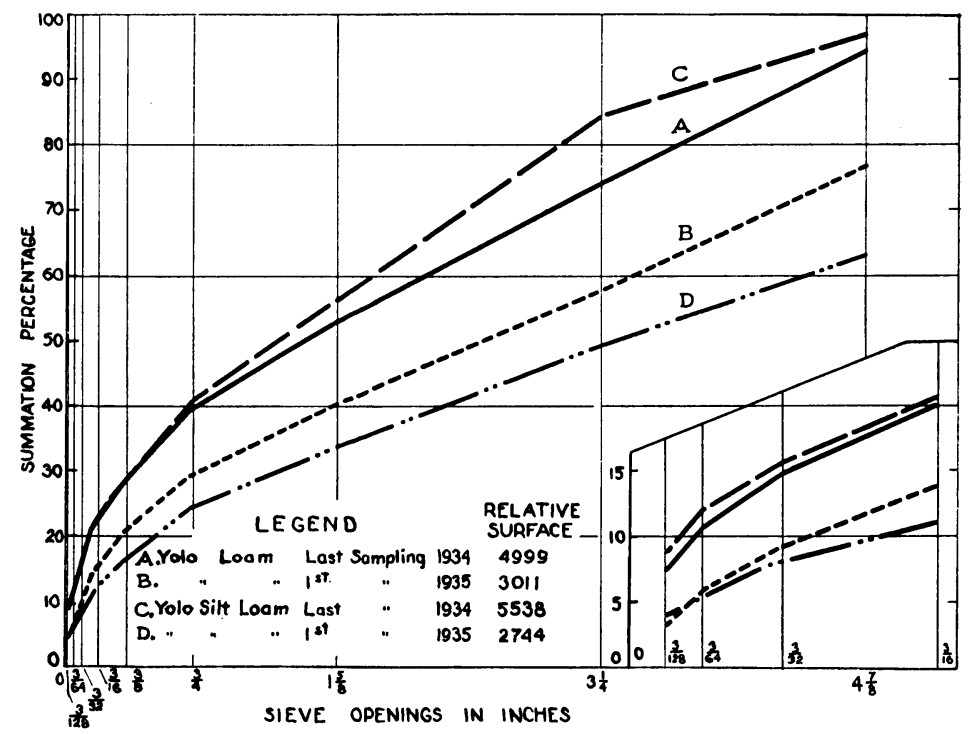

Fig. 23.-Changes in size distribution of aggregates on plot 2 of Yolo-loam and Yolo-silt-loam areas during the winter 1934-35. 


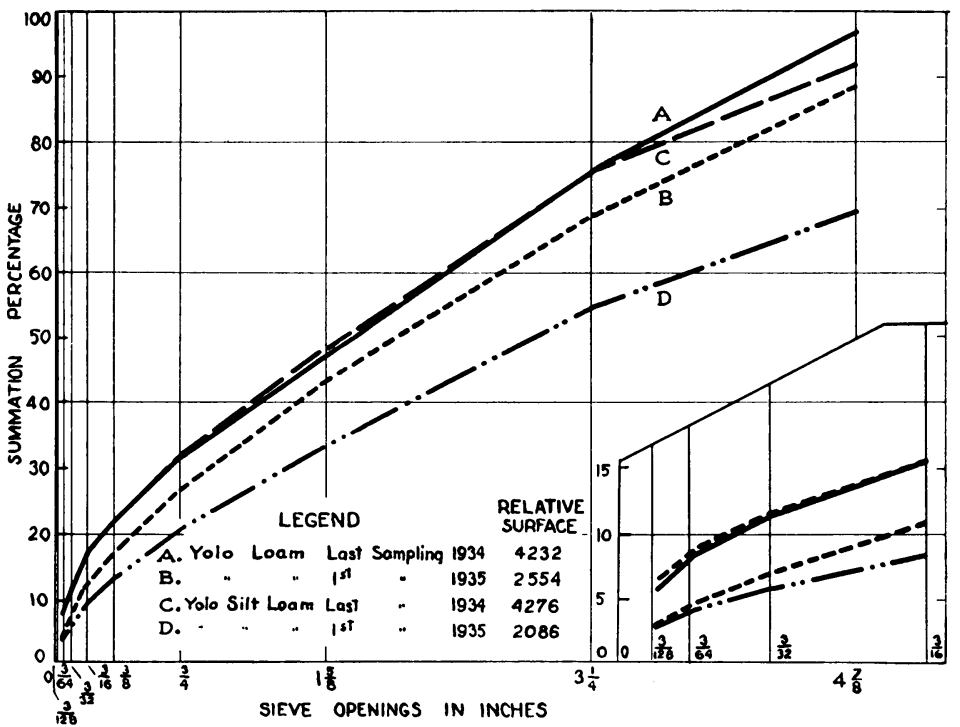

Fig. 24. - Changes in size distribution of aggregates on plot 3 of Yolo-loam and Yolo-silt-loam areas during the winter 1934-35.

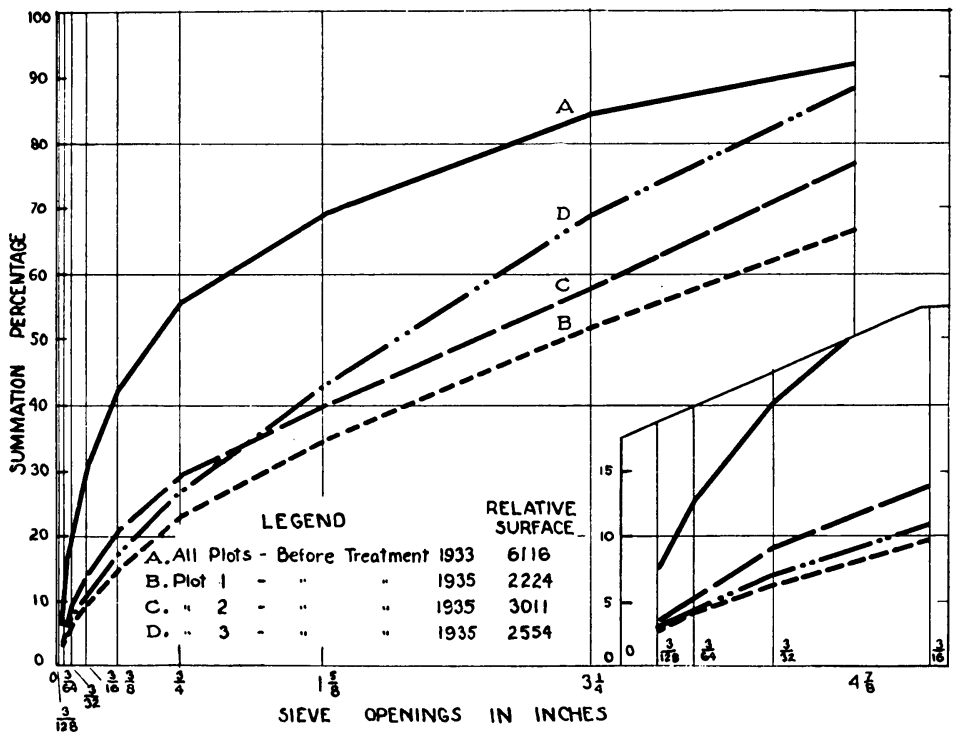

Fig. 25.- Size distribution of aggregates on all plots on Yolo loam in springs of 1933 and 1935. 
of the experiment in 1933. The data for these sampling periods are plotted in figures 25 and 26 . The tillage operations did not have a lasting effect on the size distribution of aggregates on either soil ; for the untilled plots had as much change as did the tilled plots. In fact, in 1935 on the Yolo loam, the untilled plot had the lowest relative-surface value of the

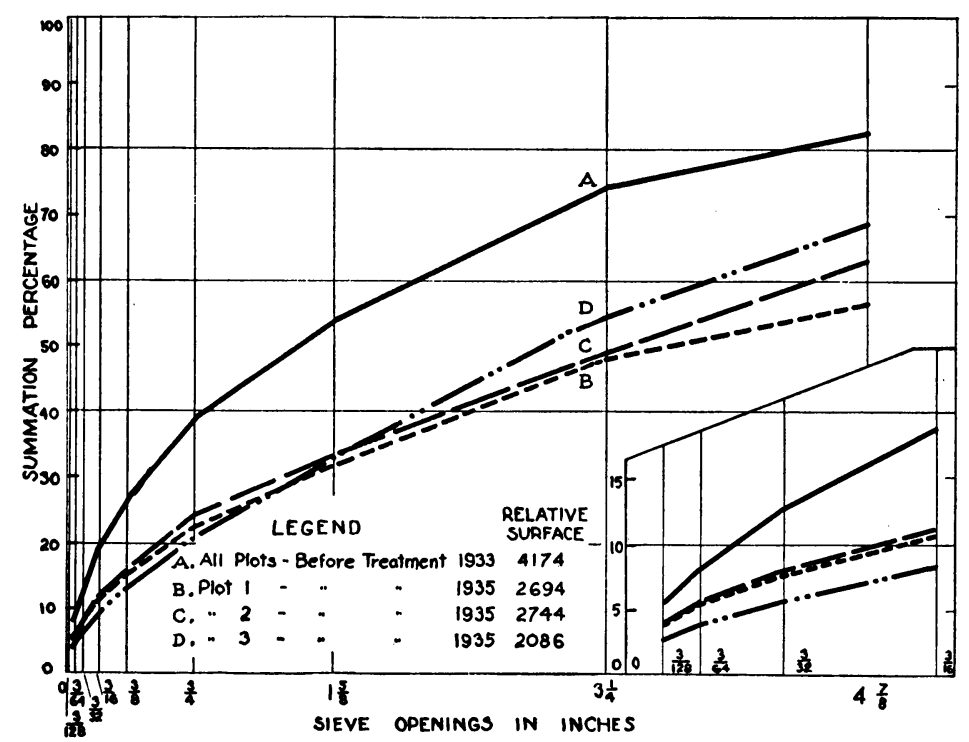

Fig. 26. - Size distribution of aggregates on all plots on Yolo silt loam in springs of 1933 and 1935.

three plots, whereas on the Yolo silt loam, the plot plowed too wet had the lowest value.

The seasonal changes over the winter period in the vicinity of Davis are somewhat similar to those obtained by irrigation treatments. This is not surprising because the winters at Davis are mild, the soils never freeze, and nearly all of the season's total rainfall of about 17 inches comes in a five-month period from December to May. The surface soils are usually wet to field capacity after the first few rains and remain so until the end of the rainy season, with seldom an opportunity for drying out.

\section{DISCUSSION}

From the data presented, and the rather consistent general tendencies observed, the air-dry sifting used throughout this work appears to give a better picture of the size distribution of aggregates in the field than when the samples are sifted moist, despite the fact that the replicate samplings are equally variable by either method. The aggregates in the 
moist condition are so weak that the mechanical action necessary for a good separation into the respective sizes is sufficient to break down some of them, so that the resultant data do not give an accurate picture of the size distribution at the time of sampling.

It is fairly certain that the method of sifting in the air-dry condition gives a good picture of size distribution just before sifting, but the question still arises as to whether or not the samples when air-dry and ready for sifting had the same condition of aggregation as that when in the field prior to sampling. The method of sampling being uniform, the change, if any, in the size distribution of aggregates must be very small because of the care with which the samples were taken. If a change in the size distribution of aggregates is brought about by air-drying the samples, then a further question arises as to how much difference there is in the size distribution of aggregates when the sample is dried in the boxes, as was the case in this work, and when drying takes place naturally in the field. These questions need further study, but at present it seems that the changes that take place during the drying process were not very great, and probably much smaller than the natural differences due to heterogeneity of the soil, so that the measurements of aggregates in the air-dry condition give a good picture of the size distribution of aggregates at the time the samples were taken.

The number of tillage operations used in preparing a seedbed is often more a matter of habitual practice than a careful consideration of the physical condition to be attained for the particular crop. Year after year, many farmers use the same tillage operations, irrespective of the physical condition of the soil. Under such practices, undoubtedly many tillage operations are performed that are wholly unnecessary. The farmer may just as well be saved the cost of performing such operations by a more careful observation of the condition of the field and the condition required for the use to which the field is to be put.

A consideration of the curves showing changes in size distribution of aggregates in preparing seedbeds shows that in a number of instances, the size distribution of the aggregates at the final fitting of the field for seeding was'not greatly different from that before any tillage operations were performed. A rather striking example of such a condition is shown in the area of Yolo clay loam prepared as a seedbed for beans (fig. 3, curves $A$ and $F$, p. 445), in which the size distribution of aggregates is almost identical before any tillage operations and after the final tillage operation.

It is a common practice, when beans and other late-planted crops are grown under irrigation, to plow and harrow, then irrigate before final 
fitting for the seedbed. In view of the information regarding the effect of irrigation following tillage operations, it seems that in many instances, at least one tillage operation may be eliminated by applying water before plowing, or at least immediately after plowing, rather than after harrowing, provided the field does not need leveling, which should always be done when the soil is fairly dry.

Because of the great influence of irrigation water in increasing the cloddiness of soils that are finely pulverized, a field soon to be irrigated should not be worked down too fine. A similar rule should be followed for fields to be left over the winter. If the field is worked up too fine, the first rains will pack and puddle the surface, and prevent later rains from penetrating so easily. Not only may this cause the removal of some of the rain water that otherwise would have been absorbed, but also the runoff may cause damage by erosion. It is especially important that fallsown crops, fallow land, and cultivated permanent crops be left loose and open and somewhat cloddy at the beginning of the rainy season. This, of course, applies only to medium- or heavy-textured soils. Leaving lighttextured soils worked up too loose may cause damage by wind movement.

In all cases where irrigation water was applied after tillage, the soil was much more cloddy than before irrigation, and in many cases it was more cloddy than before tillage. In fact, in more than half of the instances here recorded, the greater the state of pulverization before irrigation, the coarser the condition after irrigation. All irrigations considered in this work were of the basin type, where the whole surface was covered with water.

These findings would indicate that where areas are to be irrigated during the summer by the basin method-which is a common practice in deciduous orchards in the flatter valley lands of California-it is not necessary to cultivate to a fine mulch before irrigation, for this will nullify all of the pulverizing effect of tillage. Since a mulching does not conserve the field moisture by reducing evaporation where the water table is more than 6 feet from the surface $(17,19)$, it seems that the only reason for cultivating in orchards under the above conditions would be for the purpose of controlling weeds, or turning under covercrops, or putting the surface soil in a condition to reduce the loss of moisture by runoff during the rainy season.

The samples from untilled plots of the Yolo loam and Yolo silt loam soils indicate that the seasonal changes in the size distribution of aggregates are great, and that the wetting of the soil, both by winter rains and by irrigation water, brings about changes in the size distribution of aggregates that are often as great as changes brought about by tillage implements. 


\section{SUMMARY}

The present study offers a method of measuring quantitatively changes in the size distribution of aggregates and the volume weight of the soil.

Three factors which are important in these changes are tillage, irrigation, and winter rains. In general, the results of these factors are as follows :

1. Plowing caused a decrease in cloddiness and volume weight unless performed at excessive moisture contents.

2. Harrowing usually did some breaking up of clods. Disk and springtooth harrows seemed more effective than spike-tooth harrows in reducing cloddiness.

3. Rolling and leveling operations increased the volume weight and had a pulverizing effect on the very dry soils, but moderately moist soils usually showed increased cloddiness after these operations.

4. The cloddiness of soils worked up to a fine, highly pulverized condition was greatly increased by irrigation, often to a point far in excess of that before any tillage. Tilled areas that were left cloddy showed some increase in cloddiness, but not so much as those that had been highly pulverized.

5. Winter rains often have as great an influence on the size distribution of aggregates as the tillage operations or irrigations.

A general view of the data presented shows that even under fairly well controlled conditions, the results obtained by any one cultural treatment are not always the same, but fairly comparable. The differences may be due to the natural heterogeneity of the soil or to factors that could not be readily observed.

This method offers a good means of studying the effects of various tillage implements in pulverizing the soil, and from these studies, it should be possible to determine the most efficient method of preparing the soil for any desired use. Other important relations, such as seasonal changes and changes due to irrigation and subsequent drying, may be studied, which should lead to a more efficient use of irrigation water and tillage implements. 


\section{LITERATURE CITED}

1. BAVER, L. D., and H. RHodes.

1932. Aggregate analysis as an aid in the study of soil structure relationships. Jour. Amer. Soc. Agron. 24:920-29.

2. Bouyoucos, G. J. 1929. The ultimate, natural structure of soils. Soil Sci. 28:27-37.

3. Bouroucos, G. J.

1930. A new method of measuring the comparative rate of percolation of water in different soils. Jour. Amer. Soc. Agron. 22:438-45.

4. BUeHRER, T. F.

1932. The movement of gases through the soil as a criterion of soil structure. Arizona Tech. Bul. 39:1-57. fig. 12.

5. Chapman, J. E.

1927. The effects of organic matter on the tillage of a clay soil. Internatl. Soc. Soil Sci. Proc. 1:443-45.

6. Cole, R. C., and N. E. EdLefsen.

1935. A sedimentation tube for analyzing water-stable soil aggregates. Soil Sci. $40: 473-79$.

7. Culpin, C.

1936. Studies on the relation between cultivation implements, soil structure and the crop. I. Some preliminary observations on the measurement of soil structure, with a description of an instrument for measurement of soil resistance. Jour. Agr. Sci. 26:22-35.

8. Davis, C.

1931. Improvement in the soil compactometer and notes on its performance. Wye, Kent [England] South-Eastern Agr. Coll. Jour. 28:237-42.

9. Demolon, A., and S. Henin.

1932. Recherches sur la structure des limons et la synthèse des agrégats. Soil Research 3:1-9.

10. EdLefsen, N. E., and R. C. Cole.

1936. A comparison of the specific gravity balance and the pipette method of determining density of soil suspensions. Soil Sci. 42:131-36.

11. Henin, S.

1934. Sur un mode d'expression caracterisant l'etat structural des sol. Trans. 1st Comm. Internatl. Soc. Soil Sci. (Soil Physics) p. 116-20.

12. KEEN, B. A.

1931. Physical properties of the soil. 380 p. (See especially p. 235-86.) Longmans Green, London.

13. KraUse, Martin.

1931. Russche Forschungen auf dem Gebiete der Bodenstruktur. Landw. Jahrb. 73:603-90.

14. NovaK, U.

1932. Contributions to the study of soil structure: I. [Summary in German.]

Bul. Czecho-Slovak. Acad. Agr. 8:756-61. 
15. Russeli, E. W.

1934. The interaction of clay with water and organic liquids as measured by specific volume changes and its relation to the phenomena of crumb formation in soils. Roy. Soc. of London Phil. Trans., Series A 233:361-89.

16. SHaW, C. F.

1926. Soil terminology. 28 p. (Mimeo.).

17. SHAW, C. F.

1929. When the soil mulch conserves moisture. Jour. Amer. Soc. Agron. 21: 1165-71.

18. Tiulin, A. T.

1928. Some questions of soil structure: II. Aggregate analysis a help method for determining the real soil structure. Reprint from "Results of investigations of Perm. Agr. Exp. Sta. (U. S. S. R.), Div. of Agr. Chem. No. 2.”

19. VeIHMEYeR, F. J.

1927. Some factors affecting the irrigation requirements of deciduous orehards. Hilgardia 2(6):125-291.

20. Vilensky, D.

1934. Influence de l'humidité du sol sur sa structure. Trans. 1st Comm. Internatl. Soc. Soil Sci. (Soil Physies) p. 97-108. 